\title{
Capital Obsolescence and Agricultural Productivity*
}

\author{
Julieta Caunedo ${ }^{\dagger}$ and Elisa Keller ${ }^{\ddagger}$
}

February 2016

\section{ABSTRACT}

Cross-country disparities in agricultural productivity are large and on average, larger than in other sectors of the economy. This paper studies the role of capital embodied technology adoption in explaining these cross-country disparities. We construct a novel data set of second-hand prices of agricultural equipment (tractors) across countries. We then present a vintage capital model that links equipment prices to the quality and composition of the stock of capital. In particular, a) the path of the best available equipment quality in a country is linked to the evolution of the price of any piece of equipment through time; and b) the composition of the capital stock is linked to cross country differences in the price level of a piece of equipment. Using the unique characteristics of our data set, we document that countries with higher agricultural labor productivity have steeper age-price profiles for tractors with comparable characteristics. We find that quality disparities explain $24 \%$ of the differences in agricultural productivity growth across countries. Moreover, one third of the disparities in the level of productivity can be accounted for by disparities in capital embodied technology.

JEL codes: O13, O47, Q10.

Keywords: Agricultural productivity, capital embodied technology adoption, vintage capital.

\footnotetext{
${ }^{*}$ We would like to thank B. Ravikumar, D. Restuccia, M. Boldrin and seminar participants at the Cornell Macro Workshop, U. of California at Fullerton, Midwest Macro at University of Rochester, RIDGE Workshop on Growth and Development in Macroeconomics, and the Workshop on Macroeconomics Policy and Income Inequality. David Jaume provided outstanding research assistance. We would also like to thank tractorhouse.com for sharing their data with us, and the Einaudi Center and the Institute of Social Sciences seed grants at Cornell University for financial support.

${ }^{\dagger}$ Department of Economics, Cornell University.

${ }_{\ddagger}^{\ddagger}$ Department of Economics, Durham University Business School.
} 


\section{Introduction}

This paper studies the role of capital embodied technology adoption for agricultural productivity differences across countries. Cross-country disparities in agricultural productivity are large, and much larger than in other sectors of the economy (Caselli, 2005). Such disparities may arise for example, due to market distortions that generate inefficient production scales or prevent factor reallocation. Alternatively, distortions in returns to investment may discourage physical and human capital accumulation, as well as technology adoption. By now, there is an extensive literature that studies some of those mechanisms: Restuccia, Yang, and Zhu (2008) and Donovan (2014) argue for the role of disparities in the intensity of use of intermediate inputs across countries, Gollin, Lagakos, and Waugh (2014) argue for the role of sectorial differences in hours and human capital, Adamopoulos and Restuccia (2014) argue for the disparate incidence of size dependent distortions on farms across countries ${ }^{1}$. Still, disparities in adoption patterns of capital embodied technology, and hence the quality of physical capital used in production, are still unaccounted for $^{2}$. This paper fills the gap.

Detailed data on the quality and composition of the stock of capital across countries is hard to come by. However, if we take a stand on the market arrangement under which equipment goods are traded, their quality can be inferred from price data. Agents infer quality from prices, either i) because they are price takers, and understand that high quality goods are in equilibrium more expensive; or ii) because they are strategic, and understand that changes in prices generate selection on the quality of goods available in the market (Akerlof, 1970). In general, the price of a particular good holds information about the

\footnotetext{
${ }^{1}$ Restuccia, Yang, and Zhu (2008) show that labor market frictions and barriers to intermediate inputs adoption account for about $3 / 4$ of agricultural labor productivity differences across countries. The lack of intermediate goods adoption in poorer economies can be related to taxation, lack of infrastructure and farmer's insurance needs (Donovan, 2014). Adamopoulos and Restuccia (2014) show that distortions in farm size and aggregate factors can account for $1 / 2$ of disparities in agricultural productivity across countries.Gollin, Lagakos, and Waugh (2014) show that after accounting for human capital and hour disparities across sectors, the productivity gap remains.

${ }^{2}$ Most of the cross country analysis of agricultural productivity that we are aware of use Food Agriculture Organization (FAO) data for measures of the capital stocks. From FAO Stats: "the gross fixed capital stock is the value, at a point of time, of assets held by the farmer with each asset valued at "as new" prices, regardless of the age and actual condition of the assets". FAO provides also measures of 40CV tractorequivalent of machinery units. These is a measure of metric horsepower in the farm. It does not directly control for the quality of the stock, hours, etc.
} 
quality of other available goods in the market. Information about the availability of other (higher quality) goods is key to identifying disparities in the path of quality across countries. To illustrate this feature, consider changes in the price of equipment with age. Absent any distortions, there are two reasons for which the price of a piece of equipment may decay with age: physical depreciation, or economic obsolescence. The latter is the drop in prices due to the availability of higher quality goods in the market. Hence, age-price profiles can be used to infer the quality of available goods in the market.

We construct a novel dataset of prices for new and used agricultural equipment (tractors) across countries. This dataset provides observable measures of quality such as equipment horsepower, hours of use, model, brand and age. Hence, we can compute the price decay of a good with age controlling for observable measures of quality ${ }^{3}$. We document that older goods are relatively more expensive than newer ones in countries with lower labor productivity $^{4}$. For example, in countries with $10 \%$ (5\%) the agricultural labor productivity of the US, a 15 year old piece of equipment is $71 \%(95 \%)$ as valuable as a new one. But in the US, a 15 year old piece of equipment is only $60 \%$ as valuable as a new one. These disparities are sizeable, systematic, and robust to controlling for the cost (wages) of agricultural and repair workers as well as cultivated crops. To the best of our knowledge, this is the first study to document the age-price profiles of agricultural equipment (tractors) across countries.

We infer cross-country disparities in economic obsolescence and the path of available qualities in the economy from differences in observed age-price profiles. To do it, we build a parsimonious one sector growth model in which farms are allowed to operate different vintages of capital ${ }^{5}$. Equipment prices are linked endogenously to the quality and compo-

\footnotetext{
${ }^{3}$ We also merge our dataset via geolocation with characteristics of each localized market such as cultivated crops and labor costs

${ }^{4}$ We control for quality by applying hedonic techniques as in the seminal work of Griliches (1961).

${ }^{5}$ The link between adoption and capital obsolescence has been long studied in models of vintage capital (Jovanovic and Yatsenko, 2012, Benhabib and Rustichini, 1991, Chari and Hopenhayn, 1991 for the case of human capital). We contribute to this literature by proposing a tractable framework that links the profile of equipment prices, technology adoption and productivity. Such tractability allows us to quantitatively assess the role of technology adoption and quality disparities in capital stocks for differences in agricultural productivity across countries.
} 
sition of the stock of capital. A lower adoption rate induces less obsolescence in installed stocks and higher relative prices for older vs. newer vintages. But when older stocks have higher relative prices, adoption of better qualities is also discouraged. The equilibrium path of adoption in an economy trades off induced obsolescence on installed (older) equipment, with gains in productivity from better qualities. Unlike Manuelli and Seshadri (2014) where adoption is linked to the pattern of complementarity with other factors of production (labor), we focus on how adoption decisions relate to induced obsolescence in installed stocks ${ }^{6}$.In the benchmark economy, we assume countries differ exogenously in the rate of arrival of newer/better qualities. Towards the end of the paper we relax this assumption and induce different adoption rates via disparate adoption costs.

We show that under balanced growth, a) the path of the best available equipment quality in a country is linked to the evolution of the price of any piece of equipment with age; and b) the composition of the capital stock can be inferred from cross country differences in the price level of a given piece of equipment. To understand the quantitative implications of the documented differences in age-price profiles map into differences in agricultural productivity, we conduct standard growth and income accounting exercises. Using the identification restrictions posed by our model, we measure the rate of quality adoption in each country between 1980 and 2012, as well as cross-country differences in the level of quality in 2012. On average, richer countries have both higher growth rates and levels of agricultural equipment quality. For example, capital equipment quality in the agricultural sector grows $2.6 \%$ per year in the US compared to $0.7 \%$ in Brazil. We show that $24 \%$ of cross-country differences in agricultural value added growth that are unaccounted for by observable factors (labor, capital stocks and intermediate goods) can be attributed to capital quality disparities. Second, we show that about a third of the differences in income per capita in 2012 are accounted for by differences in the average quality of agricultural equipment.

The role of capital quality for disparities in agricultural productivity is sizeable. But what generates differences in adoption rates? It is possible that farm owners in different

\footnotetext{
${ }^{6}$ The countries considered in our analysis are emerging and developed economies. The use of tractors is widespread in all of them and the stocks are relatively constant in time (see Figure 6).
} 
countries face different adoption costs. In an extension of our benchmark model we model these costs explicitly. We assume a common improvement rate for the frontier quality in the world. Farmers in each country endogenously choose at which rate to adopt technologies. Distinctively from Parente and Prescott (1994), the cost structure is such that the growth rate of quality and output per worker may differ across countries. To generate divergence in growth rates, we set an adoption cost that depends on the quality of the goods used in the country, and the pace of improvement of the frontier technology (but not on its level). We find that countries with lower value added per worker, have higher adoption costs, and lower productivity growth rates on average ${ }^{7}$. We run a counterfactual exercise in which we reduce adoption costs. We find that productivity gains differ depending on the degree of capital intensity of each country. In the data, countries with higher value added per worker are also more intensive in capital, which implies that gains from reduction in adoption costs are higher at the top of the distribution of income per worker. It is likely that the quality embodied in capital and the intensity of use of such equipment are complementary to each other. In this paper we abstract away from decisions on capital intensity. We believe our results are a lower bound to the potential gains from quality adoption ${ }^{8}$.

It is also possible that differences in adoption rates are linked to disparities in the available uses of second hand equipment within each market ${ }^{9}$. Higher valuation for old equipment may delay adoption of newer ones (if adoption rules display leap-frogging), or may accelerate adoption, by increasing scrap values of older equipment. To tackle this issue, we consider an extension of our model that allows for heterogeneous farm productivity.

\footnotetext{
${ }^{7}$ There is extensive evidence consistent with adoption costs. For example, Sunding and Zilberman (2001) show that new technologies are more likely to be adopted earlier near market centers where dealers and product supports are easily available. There are also institutional constraints to adoption, as it is the case of credit availability (Hoff, Braverman, and Stiglitz, 1993), supply chains (Sims and Kienzle, 2009). Finally, input and infrastructure complementarity (McGuirk and Mundlak, 1991) are important considerations for adoption of capital embodied technology.

${ }^{8} \mathrm{~A}$ framework such as the one presented in Manuelli and Seshadri (2014) may accommodate endogenous capital intensity choices by allowing for the elasticity of substitution across alternative good qualities to differ from one

${ }^{9}$ There is an extensive literature that studies the welfare and allocative implications of markets for used durable goods. Stolyarov (2002) focuses on the volume of trade of different vintages of cars. Also looking at the market for used cars (in France and the US), Gavazza, Lizzeri, and Roketskiy (2014) study the role of heterogeneity in willingness to pay and transaction costs for welfare.
} 
Hence, farmers are heterogeneous in their valuations of quality and their willingness to pay for alternative equipment qualities. We show that in our model, heterogeneity may explain cross-country differences in the level of prices for a given quality, but that such heterogeneity does not affect capital obsolescence. The decay of the price of a good with time is not affected by disparities in the relative willingness to pay for quality. We understand that the inferred path for the best equipment quality in our benchmark is robust to distortions that affect farm level productivity.

The remaining of the paper is organized as follows. Section 2 presents our empirical evidence, Section 3 the main model. Section 4 presents the growth and income accounting exercises, while Section 5 offers a discussion of alternative frameworks that may generate disparate adoption rates across countries. Section 6 concludes.

\section{Empirical evidence}

In this section we document the evolution of agricultural tractor prices with age (age-price profile) across countries. We first report the age-price profiles for agricultural tractors of given observable characteristics. Then, we present robustness checks that control for two dimensions of cross-country heterogeneity that might influence the relationship between age and price: 1) cultivated crops and 2) wages of agricultural and repair workers.

\subsection{Data sources}

Our main dataset consists of prices of new and old agricultural tractors that we compile using information provided by Tractorhouse.com. Tractorhouse.com is a site owned by Sandhills Publishing Company, which, for the past 40 years, has specialized in publications for companies in the equipment, transportation and technology industries. Sandhills Publishing gathers information on characteristics, dealer pricing, retail and auction pricing for various types of agricultural equipment available in the market around the world. We obtained detailed data for tractor retail and auction prices across countries by the end of 2014 . 
Our main dataset consists of a total of 28,000 observations for retail prices across 13 countries and 8,550 observations for auction prices across 8 countries. It covers countries at different stages of development. For example, Brazil and Bulgaria, some of the least productive countries in our sample, feature levels of agricultural net production value per worker equal to $14 \%$ and $27 \%$ that of the US in 2010, respectively (FAO Stats). ${ }^{10}$ We also observe equipment prices for more productive economies like Canada (agricultural net production value per worker is $89 \%$ that of the US) or France (77\% as productive). For each transaction recorded in our dataset, we observe price, age, model, horsepower, use hours and location of the tractor sold. The average age of the tractors is 9 years, with a maximum age of 45 years. A detailed description of our main dataset with the list of countries and summary statistics can be found in the online appendix.

We complement our main dataset with two additional sets of data that we use for robustness checks. First, we gather information on the crops cultivated in each of the sales locations in our main dataset. Because our main dataset includes information on the country, state and city where each sale took place, we are able to match it with high-resolution micro-data recording crop yields around the world. We use EarthStat data constructed by Ramankutty, Evan, Monfreda, and Foley (2008). The data consists of agricultural census and survey information on crop land areas and yields of 175 crops measured at the smallest political units reasonably obtainable for 206 countries $^{11}$. EathStat data is available for grid sizes of 5 -arc min (which is roughly equivalent to an area of $10 \mathrm{~km}$ by $10 \mathrm{~km}$ ). We choose main crops produced in each location by constructing a 20-mile-wide grid around each sale location and search for crops with the highest recorded yields. We choose the top two crops and match their yields with our tractor price data.

Second, we complement our main dataset with wages of agricultural and repair workers in each country. We use the NBER "Occupational wages around the world" dataset.

\footnotetext{
${ }^{10}$ The agricultural net production value as complied by the FAO is gross production in physical terms multiplied by output prices at farm gate and net of the value of seeds and feeds used in production.

11 For most countries, this database main source is Agro-MAPS, a collection of subnational statistics (a joint project of FAO, the International Food Policy Research Institute, IFPRI, and the Center for Sustainability and the Global Environment, SAGE). For those countries in which Agro-MAPS was insufficiently detailed or missing, the authors used additional censuses and surveys, as it is the case for Brazil, Argentina, Mexico, Canada, India, the United States, China, Taiwan, Iraq, Somalia and Afghanistan.
} 
It provides occupational wage data for 161 occupations in 171 countries from 1983 to 2008 by calibrating observed wages into a normalized wage rate for each occupation. CHECK WHICH IS THE ONE WE USE: Wages are deflated and denominated at purchasing power parity using the corresponding deflators from Penn World Tables. Alternatively, we express wages in terms of the average cost of equipment in each country, as available in our sample.

\subsection{Analysis}

The objective of our analysis is to approximate the age-price profiles for agricultural tractors after controlling for equipment characteristics. Our econometric strategy consists of implementing hedonic pricing techniques as in Griliches (1961) and Hulten, Robertson, and Wycoff (1989). We allow for alternative profile shapes (i.e. concave, convex) and incidences of equipment characteristics. This flexibility is important as ultimately we link cross-country differences in the age-price profiles to disparities in the patterns of adoption of capital embodied technology.

Specifically, we impose a Box-Cox type of power transformations on a standard hedonic princing model:

$$
\frac{p_{i, c}^{\theta_{1}}-1}{\theta_{1}}=\gamma_{c}+\beta_{a, c} a_{i, c}+\beta \frac{X_{i, c,-a}^{\theta_{2}}-1}{\theta_{2}}+\epsilon_{i, c},
$$

where $i$ indicates a quote and $c$ a country. The dependent variable is a tractor's quoted price while the regressors include $a$ as a tractor's age in terms of the number of years since it was built and $X$ as a vector of equipment characteristics excluding age, hence " $-a "$ - that is, horsepower, use hours, brand and model. Turning to the coefficients, $\gamma_{c}$ is a country fixed effect, $\beta$ is the vector of coefficients associated to each characteristic in $X_{-a}$, while $\theta_{1}$ and $\theta_{2}$ are the shape parameters associated to prices and equipment characteristics, respectively 12. The coefficient $\beta_{a}$ shapes the relation between price and age. When $\theta_{1}$ is estimated not significantly different than zero, the LHS of equation 1 corresponds to $\log (p)$ and the

\footnotetext{
${ }^{12}$ When $\theta_{2}$ equals 1 , the coefficients $\beta$ correspond to relative prices for alternative observable characteristics of quality.
} 


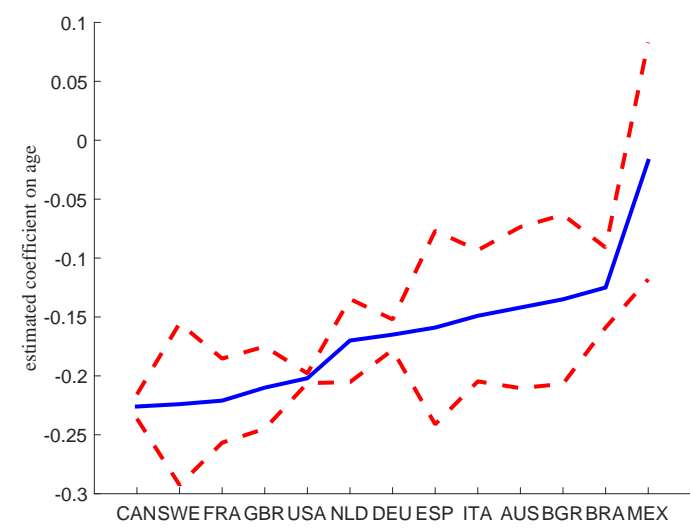

(a)

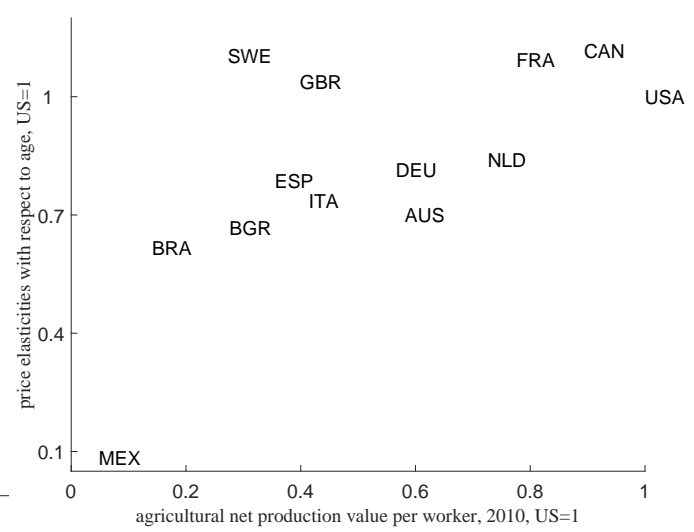

(b)

Figure 1: Estimated age coefficients across countries, $\beta_{a, c}$. Panel (a) shows our estimates for $\beta_{a, c}$ (solid line) with confidence intervals (dashed lines). Panel (b) plots the estimated elasticities of tractor prices with respect to age against agricultural net production value. Source: FAOStat and own computations based on online quotes from tractorhouse.com.

estimated parameter $\beta_{a}$ is the price elasticity with respect to age. Differently, when $\theta_{1}$ is estimated positive (negative), the age-price profile for a tractor of given characteristics $X_{-a}$ is convex (concave).

Our estimation set-up allows for two sources of cross-country heterogeneity in the ageprice profile: the coefficient $\beta_{a, c}$ and the country fixed effect. In particular, we assume that the shape parameters are identical across countries ${ }^{13}$. Country fixed effects control for country-specific characteristics that may affect the overall price level, such as taxation. We estimate equation 1 in a pooled regression by including country dummies and interaction terms for age and country dummies. The estimation is done via maximum likelihood.

Appendix B, Table 5, column (1) presents the results of our estimation. We focus on retail quotes, as these are available for a larger set of countries and refer to the online appendix for comparable results on auction data. As expected, predicted prices drop in age and hours of use, and increase in horsepower. The shape parameter in prices $\theta_{1}$ is identified significantly different from zero and positive at 0.148 . Hence, the age-price profile is convex. The shape parameter in characteristics is estimated significantly at 0.113 . The $\mathrm{R}^{2}$ of the

\footnotetext{
${ }^{13}$ In the Online Appendix we present the results of our estimation when we relax these assumptions and estimate equation 1 separately in each country.
} 


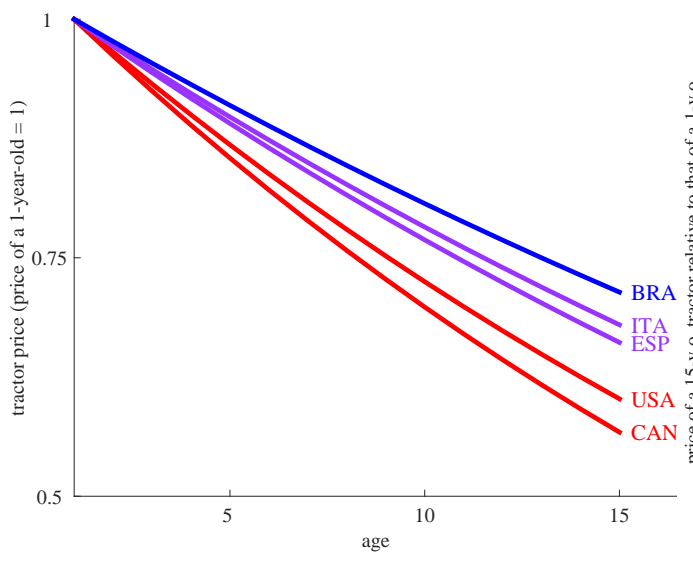

(a)

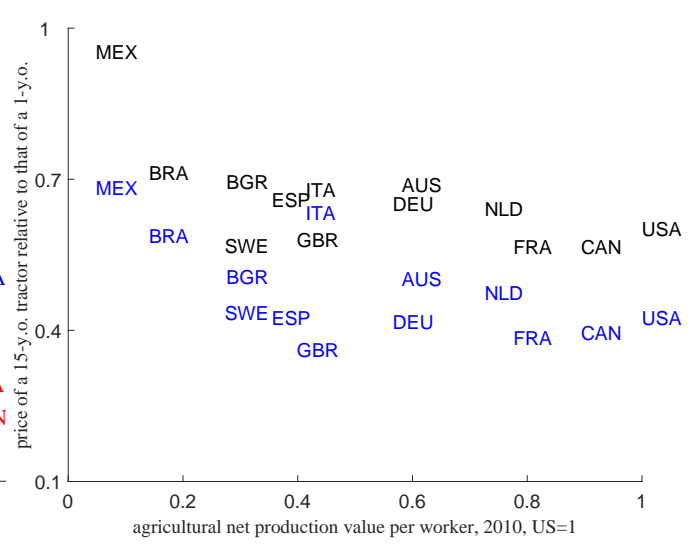

(b)

Figure 2: Age-price profiles. Panel (a) plots the predicted age-price profiles for five countries in our sample. Panel (b) shows the estimated $\beta_{a, c}$, controlling for equipment characteristics (black) and without controls (blue). Source: FAOStat and own computations based on quotes from tractorhouse.com.

estimation is 0.924 . Our estimates for the coefficients associated to hours and horsepower are -0.175 and 2.972, respectively; both significant at 5\% level. A total of 79 dummies associated to different manufacturer in the sample are included to control for brand specific differences in prices.

Figure 1 summarizes our findings regarding the estimated coefficients associated to age, $\beta_{a, c}$. Panel (a) plots the estimated $\beta_{a}$ in each country with confidence intervals. For any shape parameter $\theta_{1}$, we can describe the price elasticity with respect to age as $\beta_{a} \frac{a}{p^{\theta_{1}}}$. Therefore, the ratio of price elasticities between two countries computed at a given age and price is the ratio of estimated $\beta_{a}$ 's in the two countries. Panel (b) plots these relative elasticities with the US as the base country against our measure of agricultural labor productivity. Our estimates suggest that prices are more elastic to age in high productivity countries than they are in low productivity ones. The correlation between the fall in prices with age and agricultural net production value across countries is -0.65 .

We use our estimated model to predict the age-price profile in each country for a tractor with average equipment characteristics in our sample. Figure 2 panel (a) plots this profile for five countries in our sample, while panel (b) plots in black the predicted price of a 15-year old tractor relative to that of a 1-year old against agricultural net production 


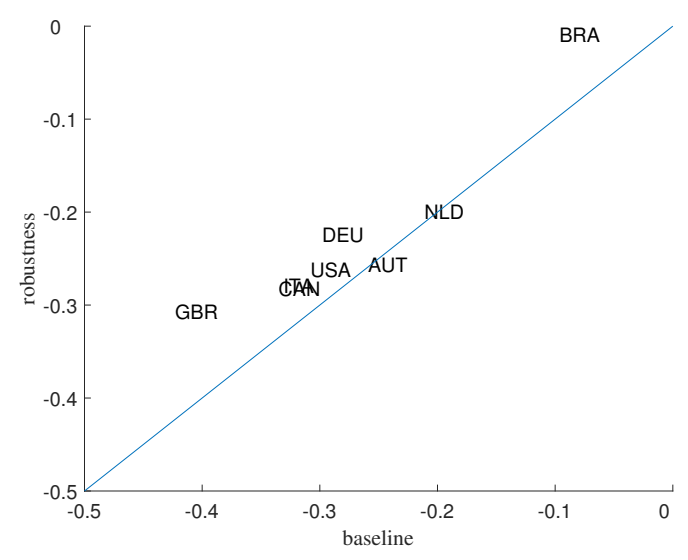

Figure 3: Robustness checks. The figure shows estimated $\beta_{a}$ without the wage and crop controls (baseline) and with the wage and crop controls (robustness). Source: own computations based on quotes from tractorhouse.com., EarthStat, OWW dataset and PennWorld Tables.

value for all the countries in our sample. The cross-country correlation between the price of the average-characteristic tractor 15-year old relative to a 1-year old and agricultural net production value per worker in 2010 is -0.63 . Finally, panel (b) compares predicted relative prices when the estimation is conduced without controlling for tractor characteristics (in blue) - that is, without including vector $X_{-a}$ in equation 1 with those using our controls (black). The differences between the two sets of relative prices in black and blue (more sizable for middle-income countries) shows the importance of controlling for capital quality while computing age-price profiles.

Robustness checks. We study the robustness of our estimated coefficients characterizing the age-price profile, $\beta_{a}$, with respect to two dimensions of cross-country heterogeneity: 1) cultivated crops and 2) wages of agricultural and repair workers. First, the degree of a tractor's mechanical wear may depend on the type of crop it was used for. For example, some geographies result in a lot more wear and tear on machinery than others. These geographical characteristics may also be associated with specific types of crops. Second, the relative price of old to new equipment may depend on the cost of factors that are substitute to capital, such as agricultural labor. In addition, the resale price of a piece of equipment can be negatively related to the relative cost of repair A big component of which is the labor cost (wage of repair workers). 
We estimate equation 1 with two additional sets of regressors: dummies for main crops cultivated in each of the sale locations, and interaction terms between hours of use and wages. The sample we use for this estimation covers at most 10 counties and about 21,000 observations of retail quotes ${ }^{14}$. For comparison, we also re-estimate equation 1 on this smaller sample. In Appendix B, Table 5, columns (2)-(5) present the results for the case where we include wage and crop controls in our estimation and for the case where we do not include these controls ("baseline").

Introducing crop and wage controls does not change the main empirical findings on the relation between age and price. Figure 3 plots the estimates of $\beta_{a}$ when we control for crops and wages ("robustness", column (5) in Table 5) against the "baseline" estimates (column (2) in Table 5). The correlation between the two sets of estimates is 0.92 .

The online appendix describes various additional robustness exercises in which we consider alternative specifications of our baseline model in equation 1.

\section{A simple model of capital obsolescence}

This section presents a general equilibrium model that links the cross-country evidence on age-price profiles of agricultural equipment to patterns of capital embodied technology adoption, and the composition of the capital stock.

We study an infinite horizon economy (subscript $t$ indicates time) populated by a continuum of homogeneous households and farms ${ }^{15}$. Households can consume and invest. Investment can be directed to accumulate capital of different quality. Quality is not directly observable, but we assume there is a mapping from observables $X_{t}$ to quality, $q\left(X_{t}\right)$. Capital quality indexes vintages, $j$, through a one-to-one mapping. The best available quality at time $t$ is $Q\left(X_{t}\right)$ with vintage $J_{t}$.

Farms produce final output with a constant returns technology that uses capital ser-

\footnotetext{
${ }^{14}$ The reduction the size of sample occurs due to missing location data that does not allows us to match prices to crops. In addition, wage data by occupations is not available for every country in our sample.

${ }^{15}$ We drop the homogeneity assumption in section 5.2
} 
vices, labor $n$ and land, $l$. Capital services are the product of the number of machines of a particular quality and their corresponding quality, $q\left(X^{j}\right) k^{q_{j} 16}$. Capital of alternative qualities is perfectly substitutable. We call the set of vintages used in production, $A_{t} \equiv\left\{j \leq J_{t}: k_{t}^{q_{j}}>0\right\}$. The share of capital (labor) in production is $\alpha_{k}\left(\alpha_{n}\right)$ and the share of land is $\alpha_{l}$. The production function is

$$
y_{t}=\left(\sum_{j \in A_{t}} q_{j} k_{t}^{q_{j}}\right)^{\alpha_{k}} l_{t}^{\alpha_{l}} n_{t}^{\alpha_{n}}
$$

The supply of labor and land is inelastic at $N$, and $L$, while the supply of capital of each vintage is determined by households.

In this section of the paper we abstract away from the problem of adoption of quality, so we assume the best available quality arrives at a constant growth rate, $\mu$.

$$
Q_{J_{t+1}}=Q_{J_{t}}(1+\mu)
$$

This arrival rate is country specific and will be endogenized in section 5.1.

\subsection{Households}

Households rent capital and labor to farms at market prices. Given the arrival rate of vintages of capital, households decide how much to invest in each capital quality, $x_{t}^{q_{j}}$. Let $A_{t}^{c}$ be the set of vintages that the household holds in its portfolio, $A_{t}^{c} \equiv\left\{j \leq J_{t}: k_{t}^{q_{j}}>0\right\}$. The stock of capital of a given vintage has a physical depreciation of rate $\delta$ each period. A particular vintage is retired at random, with the realization of a shock $\chi$ which is distributed Poisson with intensity $\lambda>\delta$. The random variable $\chi$ takes two values, $\chi=\{1,0\}$, where 0 corresponds to retirement and occurs with probability $1-\exp (-\lambda)$ each period. Hence, the expected lifetime of a stock of vintage $j$ is $T(j)=\frac{1}{\lambda}$.

\footnotetext{
${ }^{16}$ This implies that $x$ machines of quality $2 q$ yield the same services as $2 x$ machines of quality $q$. This functional form can be generalized to break this mapping.
} 
The household problem is:

$$
\max _{c_{t},\left\{x_{t}^{q_{j}}, k_{t+1}^{q_{j}}\right\}_{j \leq J_{t+1}}} \sum_{t=0}^{\infty} \beta^{t} U\left(c_{t}\right)
$$

subject to:

$$
\begin{gathered}
c_{t}+\sum_{j \in A_{t+1}^{c}} \pi_{t}^{q_{j}} x_{t}^{q_{j}} \leq \sum_{j \in A_{t}^{c}} r_{t}^{q_{j}} k_{t}^{q_{j}}+w_{t} n_{t}+r_{t}^{l} l_{t}, \\
\left(k_{t+1}^{q_{j}}-k_{t}^{q_{j}}(1-\delta) \chi\right)=x_{t}^{q_{j}} \quad \text { for all } j \in A_{t+1}^{c}, \\
q_{j} \leq Q_{J_{t+1}} \text { for all } j \in A_{t+1}^{c} \quad \text { and } \quad x_{t}^{q_{j}} \geq 0, \\
Q_{J_{t+1}}=Q_{J_{t}}(1+\mu),
\end{gathered}
$$

where $\pi_{t}^{q_{j}}$ is the price of investment in vintage $j$ relative to consumption goods.

The optimality conditions with respect to capital of alternative vintages are:

$$
U^{\prime}\left(c_{t}\right) \geq \beta U^{\prime}\left(c_{t+1}\right) \frac{\pi_{t+1}^{q_{j}}}{\pi_{t}^{q_{j}}}\left[\frac{r_{t+1}^{q_{j}}}{\pi_{t+1}^{q_{j}}}+(1-\delta)\right] \exp (-\lambda), \quad j \in A_{t+1}^{c}
$$

Hence, if the return on a particular vintage is relatively low the household may decide not to accumulate capital of such vintage.

\subsection{Farms}

The problem of each farm in the economy is to maximize profits by choosing land, labor and capital (of different vintages). Let $A_{t}^{c}$ be the set of vintages that the farm rents $A_{t} \equiv$ $\left\{j \leq J_{t}: k_{t}^{q_{j}}>0\right\}$. To ease notation, define $q_{j}=q\left(X^{j}\right)$. The farmer's problem is

$$
\max _{\left\{k_{t}^{q_{j}}\right\}_{j \leq J}, l_{t}, n_{t}}\left(\sum_{j \in A_{t}} q_{j} k_{t}^{q_{j}}\right)^{\alpha_{k}} l_{t}^{\alpha_{l}} n_{t}^{\alpha_{n}}-w_{t} n_{t}-r_{t}^{l} l_{t}-\sum_{j \in A_{t}} r_{t}^{q_{j}} k_{t}^{q_{j}}
$$

subject to:

$$
q_{j} \leq Q_{t} \text { for all } j \in A_{t},
$$




$$
Q_{J_{t+1}}=Q_{J_{t}}(1+\mu)
$$

Hence, the farm can decide to use vintages that have strictly lower quality than the top available technology.

The demand of capital of vintage $i, k^{q_{i}}$, is characterized by the optimality condition,

$$
\alpha_{k} y_{t} \frac{q_{i}}{\sum_{j \in A_{t}} q_{j} k_{t}^{q_{j}}} \leq r_{t}^{q_{i}}
$$

If $r_{t}^{q_{i}}>\alpha_{k} y_{t} \frac{q_{i}}{\sum_{j \in A_{t}} q_{j} k_{t}^{q_{j}}}$ then $k^{q_{i}}=0$. Otherwise, capital demand is positive. The equilibrium quantity of capital used in production is fully determined by the household supply. Due to the perfect substitutability across capital vintages, none of them is strictly necessary for production. In particular, the marginal product of capital of a particular vintage $j$ is positive and bounded away from infinity as the quantity of capital goes to zero $k_{t}^{q_{j}} \rightarrow 0$ (i.e. $\left.\lim _{k^{q_{i} \rightarrow 0}} \alpha y_{t} \frac{q_{i}}{\sum_{j \in A_{t}} q_{j} k_{t}^{q_{j}}}<\infty\right)$, except when only one vintage is used in production. Let $\bar{j}$ be the best adopted vintage in production.

Proposition 1 The set of vintages used in production, $A_{t}$, is a connected interval with some lower and upper bound, $A_{t} \equiv\left[\underline{j}_{t}, \bar{j}_{t}\right]$.

\subsection{Equilibrium Prices}

The return to any vintage of capital $j$ corresponds to its marginal product of capital. If $p_{t}^{k^{q_{j}}}$ is the price of capital with quality $q_{j}$ at time $t$, it should satisfy

$$
r_{t+1}^{q_{j}}=p_{t}^{k^{q_{j}}} \frac{R_{t+1}}{(\exp (-\lambda))}-p_{t+1}^{k^{q_{j}}}(1-\delta)
$$

where $R_{t+1}$ is the interest rate in the market, i.e. the value of the return to a unit of consumption foregone today $R_{t+1}^{-1}=\beta \frac{U^{\prime}\left(c_{t+1}\right)}{U^{\prime}\left(c_{t}\right)}$. By arbitrage, the price of capital with quality $q_{j}$ equals the relative price of investment to consumption goods, $p_{t}^{k^{q_{j}}}=\pi_{t}^{q_{j}}$. The pricing equation in (2) implies that at the equilibrium prices, the household is indifferent between any capital quality used in production (i.e. higher quality vintages are also relatively more 
expensive). If it invests in the top quality only, returns to capital services are the highest, as it is long run growth.

For older vintages of capital, the law of motion of the stock of capital is:

$$
\begin{array}{lr}
k_{t+1}^{q_{j}}=k_{t}^{q_{j}}(1-\delta) & \text { if } \chi=1, \\
k_{t+1}^{q_{j}}=0 & o / w .
\end{array}
$$

For the top available technology, investment is chosen optimally. Hence, the supply of capital for a given vintage decays after an initial accumulation period. Capital supply fully determines equilibrium prices in the economy. The price of capital of vintage $j$ at time $t$ is,

$$
p_{t}^{k^{q_{j}}}=\sum_{s=t+1}^{\infty} \frac{(1-\lambda)^{s-t}(1-\delta)^{s-(t+1)}}{\prod_{h=0}^{s-t+1} R_{t+1+h}} \alpha y_{s} \frac{q_{j}}{\sum_{j \in A_{s}} q_{j} k_{s}^{q_{j}}}
$$

Conditional on the quality of a given good, the price of older equipment is lower than the price of newer equipment. The rate of decay depends not only on structural parameters of the model, such as the physical depreciation rate and exogenous retirement rate, but also on equilibrium outcomes, such as the optimal choice of vintages used in production, $A_{t}$. We make these statements formal once we characterize the balanced growth path of the economy.

\subsection{Balanced growth path (BGP)}

In this section we show there exist a BGP and characterize equilibrium allocations and prices of equipment. Definition: A balanced growth path (BGP) is an allocation where output and efficiency units of capital grow at a constant rate, physical capital, labor, land and the distance between the best and worst available vintage used in production are constant.

Given that all farms are identical, it is possible to describe the aggregate production 
function of this economy as:

$$
Y_{t}=\left(\sum_{j \in A_{t}} q_{j} k_{t}^{q_{j}}\right)^{\alpha_{k}} N^{\alpha_{n}} L^{\alpha_{l}}
$$

where $N$ is the aggregate labor supply and $L$ the aggregate land supply. Output per worker is

$$
\widetilde{y}_{t}=\left(\sum_{j \in A_{t}} q_{j} \widetilde{k}_{t}^{q_{j}}\right)^{\alpha_{k}} \widetilde{l}^{\alpha_{l}}
$$

where $\widetilde{x}_{t}=\frac{x_{t}}{N}$. Let $k_{t}$ be the aggregate stock of capital per worker without controlling for efficiency units, i.e. $\sum_{j \in A_{t}} k_{t}^{q_{j}}=k_{t}$.

Proposition 2 There exist a BGP in which investment in efficiency units of capital $\pi^{q_{\bar{j}_{t}}} \widetilde{x}_{t}$, consumption and output per worker, $\widetilde{c}_{t}$ and $\widetilde{y}_{t}$, and the price of capital for the best available technology, $\pi^{q_{\bar{j}}}$, grow proportionally to the quality of the best available vintage in the market, $\alpha_{k} \mu$. Investment in the stock of capital, $\widetilde{x}_{t}$, and the stock of capital per worker, $\widetilde{k}_{t}$ are constant. The quality of the bounds for the best and worst vintages used in production, $\underline{j}_{t}$ and $\bar{j}_{t}$ respectively, grow proportional to the growth rate of the best available quality in the market, $g_{q_{\bar{j}_{t}}}=\mu$.

Predicted prices ${ }^{17}$. Now we can characterize the relationship between the price of new and old equipment with the rate of arrival for the best quality in the market $\mu$ and the vintage composition of the capital stock along the BGP. Interest rates and the growth rate of quality are constant at $R$ and $\mu$, respectively. Let $p_{t}^{k_{j+1}}(0)$ be the price of a new tractor at time $t$, that has quality $q_{\bar{j}_{t+1}}$. This price corresponds to the present discounted value of capital services throughout its expected lifetime,

$$
p_{t}^{k_{j+1}}(0)=\alpha_{k} q_{\bar{j}_{t+1}}^{\alpha_{k}} \frac{(1-\lambda)}{R} \sum_{s=t+1}^{\infty}\left(\frac{(1-\lambda)(1-\delta)}{(1+\mu)^{1-\alpha_{k}} R}\right)^{s-t+1} \frac{\widetilde{l}^{\alpha_{l}}}{\left(\widehat{q_{\bar{j}}} \widehat{\delta} \widetilde{k}\right)^{1-\alpha_{k}}}
$$

where $\widehat{q}_{s}=\left(\frac{k_{\overline{j_{s}}}}{k_{s}}+\sum_{j \in A_{s}-\overline{j_{s}}} \frac{q_{j}}{q_{\overline{j_{s}}}} \frac{k_{j}}{k_{s}}\right)^{1-\alpha_{k}}$ is a measure of the vintage composition of the stock of capital along the BGP. In an abuse of interpretation, we will refer to this measure as "the average quality" of the stock of capital.

\footnotetext{
${ }^{17} \mathrm{~A}$ detailed derivation of these prices can be found in the online appendix.
} 
Let $\widehat{p}_{t}^{k_{i}}(a)$ be the price of an "a" years old tractor of quality $q_{i}$. It equalizes:

$$
\widehat{p}_{t}^{k_{i}}(a)=(1-\delta)^{a} p_{t}^{k_{i}}(a)=\frac{\alpha_{k} q_{\bar{j}_{t+1}^{\alpha}}^{\alpha} \widetilde{l}^{\alpha_{l}}}{\left(\widehat{q_{\bar{j}}} \widehat{\delta} \widetilde{k}\right)^{1-\alpha_{k}}}\left(\frac{(1-\delta)}{(1+\mu)}\right)^{a} \frac{\frac{(1-\lambda)}{R}}{1-\frac{(1-\lambda)(1-\delta)}{(1+\mu)^{1-\alpha_{k} R}}}
$$

We can define an effective discount rate, $\psi=\frac{(1-\lambda)(1-\delta)}{(1+\mu)^{1-\alpha_{k} R}}<1$ and a constant $\lambda_{i t}=$ $\frac{\alpha_{k} q_{\bar{j}_{t+1}}^{\alpha_{k}} \widetilde{l}^{\alpha_{l}}}{\left(\widehat{q_{\bar{j}}} \widetilde{\delta}\right)^{1-\alpha_{k}}} \frac{(1-\lambda)}{R}$. If we take logs over the pricing equation, we obtain the main condition that identifies disparities in the pattern of quality adoption across countries. The log of the price of an a-years old tractor depends linearly on age, with a coefficient that is a function of physical depreciation and the arrival of new available technologies to the market (obsolescence).

$$
\ln \left(\widehat{p}_{t}^{k_{i}}(a)\right)=\ln \left(\frac{\lambda_{i t}}{1-\psi}\right)+a \ln \left(\frac{(1-\delta)}{(1+\mu)}\right)
$$

If we run a regression of the log of prices on age, differences in $\mu$ are identified from the coefficient associated to age and a country specific physical depreciation rate. In addition, the constant of such regression identifies disparities in the level of average quality used in production, as characterized by $\lambda_{i t}{ }^{18}$. We use this specification as a benchmark for the income and growth accounting exercises presented in the next section. The two key ingredients of the model that allows us to identify the path for the best available technology and the quality of the stock of capital are i) the balanced growth assumption (which pins down the composition of the capital stock given an arrival rate $\mu$ ); and ii) competitive rental markets for capita of different vintages (which validates the price characterization in equation .

\section{The role of capital embodied technology for agricul- tural productivity}

We study the role of capital embodied technology for labor productivity in the agricultural sector via standard growth and income accounting exercises. First, we identify the cross-

\footnotetext{
${ }^{18}$ When estimating disparities in the level of quality we allow capital and land shares to differ across countries.
} 
country paths of capital embodied technology in the agricultural sector from prices of old and new agricultural tractors. Second, we run a standard growth accounting exercise to quantify the role of capital embodied technology for labor productivity growth over the period 1980-2012. Last, we run a development accounting exercise where we study the role of cross-country differences in capital embodied technology for the observed variance in agricultural value added per worker in 2012. Our income and growth accounting exercises are both computed assuming that each economy in our study is on its balanced growth path.

We consider 13 countries: United States, Canada, France, Netherlands, Australia, Germany, Great Britain, Italy, Spain, Bulgaria, Sweden, Brazil, and Mexico. We use two main data sources: the Statistical Database of the Food and Agricultural Organization of the United Nations (FAOStat) and our main dataset described in Section 2.

\subsection{Identification of the level and path of equipment quality}

We assume countries differ from one another on four exogenous dimensions (parameters):

- factor shares, $\alpha_{k}, \alpha_{l}$ and $\alpha_{n}$;

- endowments of land per worker in the agricultural sector, $\widetilde{l}$;

- the depreciation of physical capital, $\delta$;

- the path of capital quality, described by the arrival rate of the best available technology, $\mu$, and the level of the top quality operated in a given year $q_{\bar{j}}$.

Notice that differences in the parameters describing the arrival rate of the best available technology and the level of the best adopted technology, imply differences in the average quality of installed capital at each point in time.

Factor shares are taken from the FAO-based datasets published by the United States Department of Agriculture Economic Research Service (USDA-ERS) in relation to the study of Fuglie (2015). In 2012, the labor share in the US is $28 \%$ and the capital share is $21 \%$, while in Brazil the labor and capital shares are $60 \%$ and $26 \%$, respectively. On average, less 
productive countries are less intensive in physical capital than more productive one (further details are in Appendix B.1).

USDA-ERS also publishes total agricultural land in hectares of "rainfed cropland equivalents." This is the sum of rainfed cropland (weight equals 1.00), irrigated cropland (weight varies from 1.00 to 3.00 depending on region) and permanent pasture (weight varies from 0.02 to 0.09 depending on region). We divide these estimates by the number of workers in agriculture and use it as our measure of land endowment. We normalize land per worker to equal 1 in the US. In 2012, Australia has about 2 times the land endowment of the US, while the Netherlands has about $10 \%$ the land endowment of the US.

We measure the depreciation rate of physical capital from the decay in price of a piece of equipment with hours of use. Our identification strategy consists of using the baseline estimates in Section 2 to predict, for each country, the price of a synthetic tractor with average characteristics (including age) at different hours of usage. From these hours-price profiles we then infer the physical depreciation rates across countries. Details of our identification strategy can be found in Appendix B.2, which also shows the inferred depreciation rates in Table 4 . The cross-country average of these depreciation rates is $2.36 \%$.

Path of capital quality. We start by showing the identification of the growth rate of capital embodied technology (capital quality), $\mu$. As established in the previous section, equation 3.4, the rate at which the price of a tractor of a given quality evolves with age is informative on the growth rate of capital quality in an economy. In our model, regressing the logarithm of the price of a tractor on its age and a constant allows identification of the rate of arrival $\mu$ up to the depreciation rate of physical capital. Our model assumes a one-to-one mapping between age and quality. Hence, at any point in time, tractors of a given age have identical quality. This is certainly not the case in the data. The correct data analog of our model-implied regression is one in which we include controls for tractors' characteristics. In line with the hedonic pricing literature, we augment our model-implied regression with measures of observable characteristics for each tractor:

$$
\ln \left(\widehat{p}_{i, c}\right)=\gamma_{1, c}+\gamma_{2, c} a_{i, c}+\beta \frac{X_{i, c,-a}^{\theta_{2}}-1}{\theta_{2}}+\epsilon_{i, c}
$$




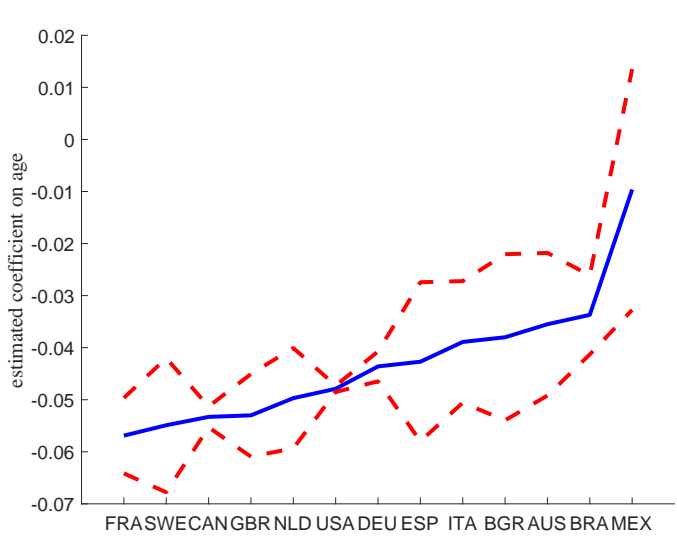

(a)

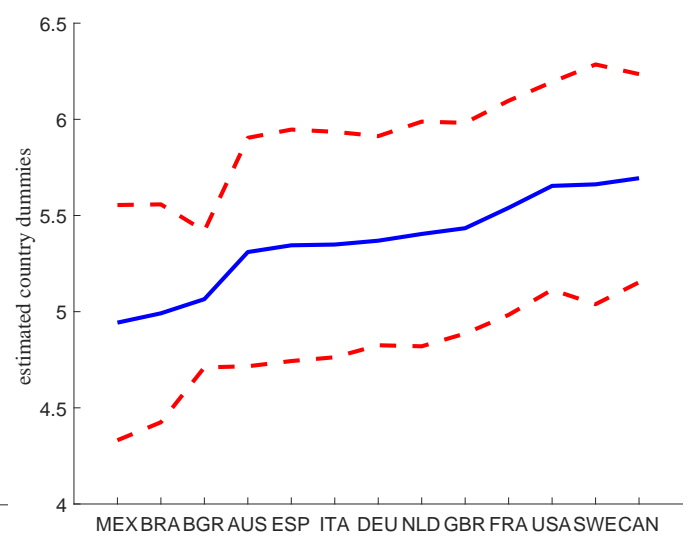

(b)

Figure 4: Panel (a): Estimated country-specific coefficients on age $\gamma_{2, c}$ (solid line) with confidence intervals (dashed lines). Panel (b): Estimated country-specific intercepts, $\gamma_{1, c}$ (solid line) with confidence intervals (dashed lines). Source: own computations based on quotes from tractorhouse.com.

where $i$ is a quote and $c$ is country, $\gamma_{1, c}$ is a country fixed effect, $\gamma_{2, c}$ is a country-specific coefficient on age, $X_{-a}$, is a vector of equipment characteristics excluding age, $\beta$ is the vector of coefficients associated to each of these characteristics, $\epsilon$ is an error term which is assumed normally distributed. Informed by our theory, we include fixed effects and countryspecific coefficients on age ${ }^{19}$. Equipment characteristics include: horsepower, total hours divided by age, model, manufacturer. We allow for non-linear specifications: $\theta_{2}$ is a shape parameter associated to equipment characteristics aside from age, $X_{-a}$. The estimation is done via maximum likelihood. Estimated country-specific coefficients on age and country fixed effects are shown in Appendix B, Table 6.

Our estimates of the country-specific coefficients on age are shown in Figure 4, panel (a). Figure 5 shows the inferred country-specific arrival rate of improved quality $\mu$. On average, we find higher growth rates of capital quality for richer countries. Our inferred growth rate of capital quality has a correlation of 0.57 with agricultural value added per worker. Capital quality in the agricultural sector grows $2.6 \%$ per year in the US compared to $0.7 \%$ in Brazil.

\footnotetext{
${ }^{19}$ Equation 3.4 dictates that country-specific $\mu$ and $\delta$ imply country-specific coefficients on age.
} 

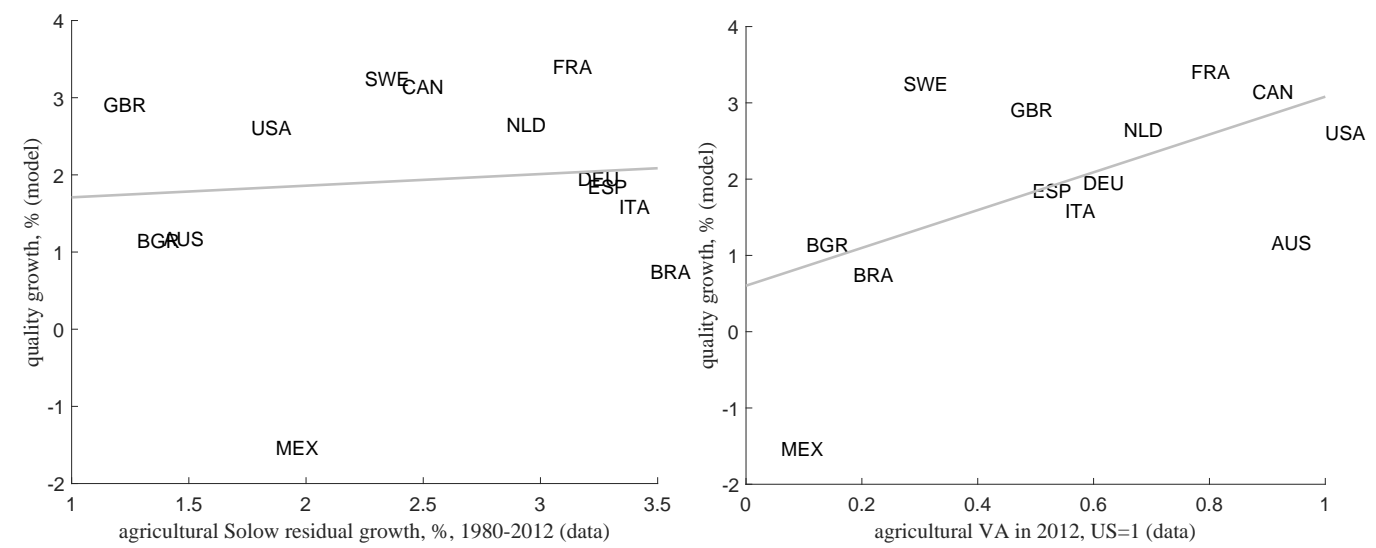

Figure 5: Inferred growth rate of capital quality, $\mu$. Agricultural value added in year 2012 is computed from the USDA-ERS dataset by multiplying the value of gross agricultural production per worker by 1 minus the sum of intermediate inputs factor shares. Source: FAOStat and own computations based on quotes from tractorhouse.com.

To understand the plausibility of the inferred growth of agricultural capital quality we study the implications of our model for a non-targeted moment, the stock of capital. As shown in Figure 6, the number of tractors is relatively stable for the countries in our sample. We compare our model-implied differences in steady state quantity of capital per worker, $\widetilde{k}$, to differences in the average number of tractors per worker observed in the data over the period 1980-2012. Differences in the steady state capital across countries are a function of $\mu$ (once controlling for the depreciation rate, factor shares and land endowments, which we take from the data). Figure 7 plots a correlation between model and data moments of 0.82 .

Given the arrival rate of quality and the top quality operated in a given year, we can compute the path for average quality. We measure cross-country disparities in the top technology operated in a given year, $q_{\bar{j}_{t+1}}$, from the country-specific dummies as predicted by our model (equation 4). Details on the identification strategy are in Appendix B.3. Figure 4, panel (b), shows the estimated country-specific dummies, while Figure 8, reports average quality in each country in 2014 relative to the US:

$$
\frac{q_{\bar{j}, c, 2014} \widehat{q}_{\bar{j}, c}}{q_{\bar{j}, U S, 2014} \widehat{q}_{\bar{j}, U S}} .
$$




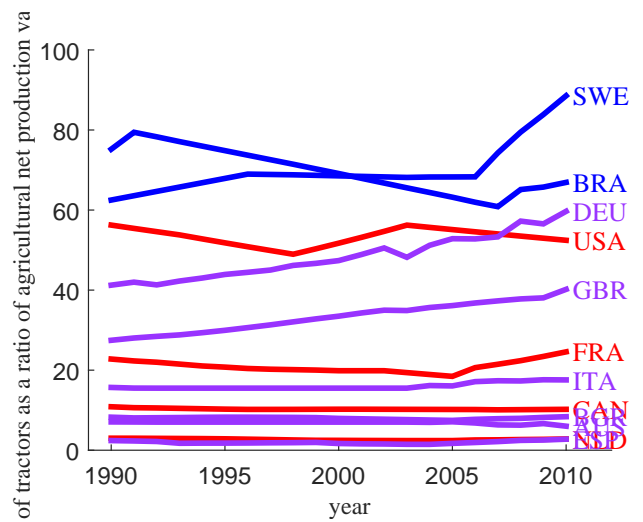

(a)

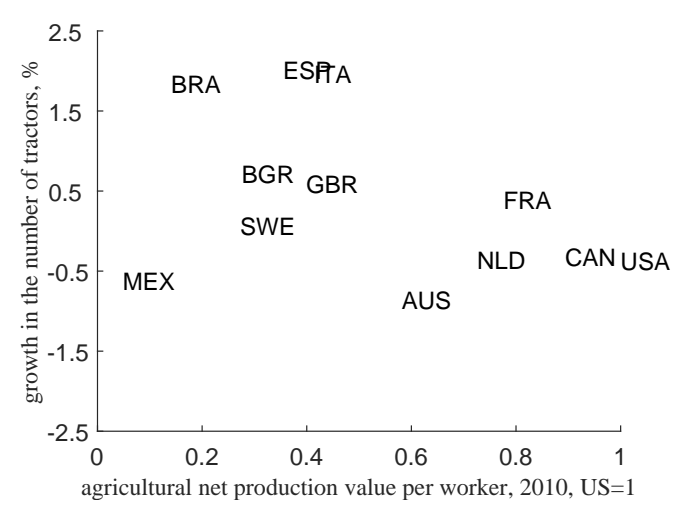

(b)

Figure 6: Number of tractors. The colors of the lines in panel (a) reflect the country's rankings with respect to agricultural net production value in 2010: from lowest in blue to highest in red. The growth rate in panel (b) refer to the period 1990-2010. Source: FAO.

Recall that the term $\widehat{q}_{\bar{j}}$ reflects the range of capital qualities operated in a country and, under balance growth assumption, is only a function of physical depreciation and the growth rate of capital quality (up to the share of capital):

$$
\widehat{q}_{\bar{j}, c}=\left(\sum_{i=1}^{1 / \gamma}\left(\frac{1-\delta_{c}}{1+\mu_{c}}\right)^{i-1}\right)^{1-\alpha_{K}}
$$

On average, we measure a higher average quality of agricultural capital in richer countries compared to poor countries in 2014. Our inferred average capital quality has a correlation of 0.39 with agricultural value added per worker. The average quality of agricultural capital in the US is 11.7 times larger that in Brazil.

\subsection{Accounting exercises}

In this section we study the role of capital quality for agricultural value added per worker.

We start from the standard description of agricultural production in Caselli (2005):

$$
\widetilde{y}^{d}=\underbrace{A}_{\text {Solow residual }} \widetilde{k}^{\alpha_{k}} \widetilde{l}^{\alpha_{l}}
$$



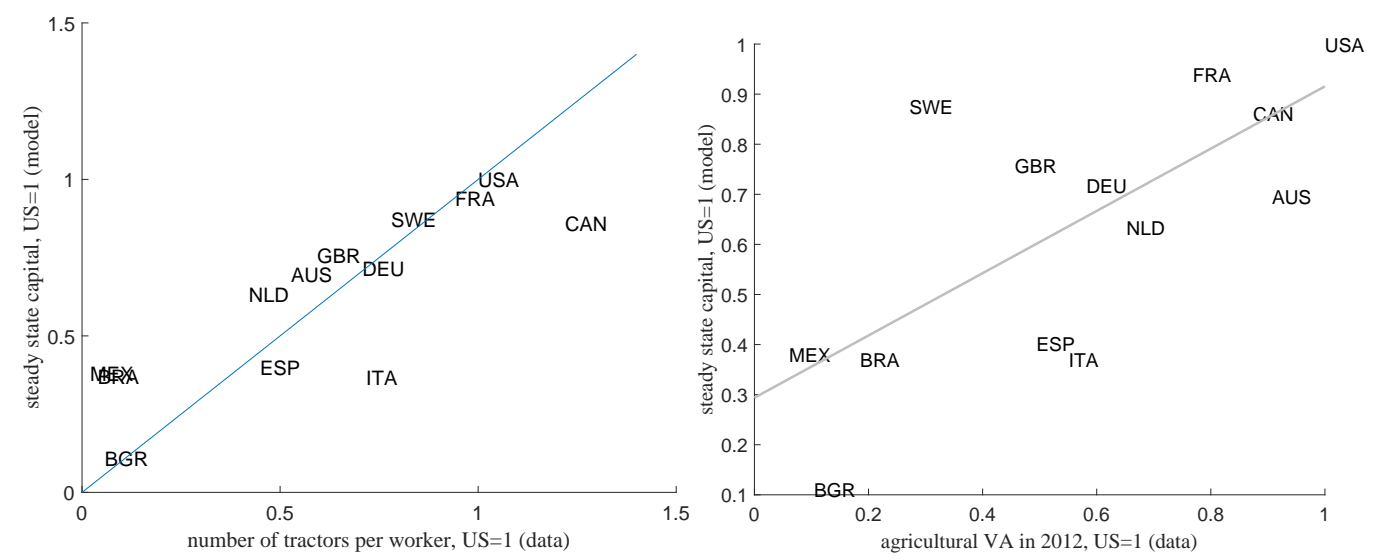

Figure 7: Observed number of tractor used vs. steady state quantity of tractors. Agricultural value added in year 2012 is computed from the USDA-ERS dataset by multiplying the value of gross agricultural production per worker by 1 minus the sum of intermediate inputs factor shares. Source: FAOStat and own computations based on quotes from tractorhouse.com.

where $\widetilde{y}^{d}$ is observed agricultural value added and $A$ is the Solow residual. Our model identifies part of the Solow residual as capital quality. Assuming balanced growth, value added per worker in our model reads:

$$
\widetilde{y}=\left(q_{\bar{j}} \widehat{q}_{\bar{j}}\right)^{\alpha_{k}} \widetilde{k}^{\alpha_{k}} \widetilde{l}^{\alpha_{l}}
$$

We can then write:

$$
\begin{aligned}
& \widetilde{y}^{d}=\operatorname{Res} \widetilde{y} \\
& \widetilde{y}^{d}=\underbrace{\operatorname{Res}\left(q_{\bar{j}} \widehat{q}_{\bar{j}}\right)^{\alpha_{k}}}_{\text {Solow residual }} \widetilde{k}^{\alpha_{k}} \widetilde{l}^{\alpha_{l}},
\end{aligned}
$$

where Res is the measure of our model's ignorance - that is, Res $=1$ when our model replicates the value added per worker in the data exactly. Equation 5 is the benchmark for our growth and income accounting exercises.

Growth accounting. We first study the role of adoption patterns of capital embodied technology for productivity growth in agriculture. We use our model to perform a growth accounting exercise along the lines of Solow (1957) and Jorgenson and Griliches (1967). 


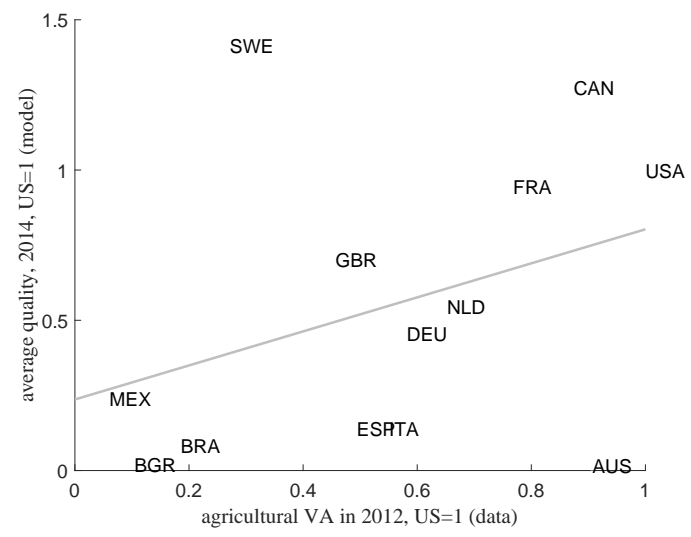

Figure 8: Inferred average capital quality in 2014, $q_{\bar{j}_{2014}} \widehat{q}_{\vec{j}}$. Agricultural value added in year 2012 is computed from the USDA-ERS dataset by multiplying the value of gross agricultural production per worker by 1 minus the sum of intermediate inputs factor shares. Source: FAOStat and own computations based on quotes from tractorhouse.com.

Given our production function in balanced growth and equation 5, we can relate the growth rate of agricultural value added per worker to the path of capital quality:

$$
g_{\widetilde{y}, c}^{d}-\alpha_{k, c} g_{\widetilde{k}, c}-\alpha_{l, c} g_{\widetilde{l}, c}=\alpha_{k, c} g_{q, c}+g_{R e s, c},
$$

where $g$ indicates a growth rate. The LHS of this last equation is the growth rate of the Solow residual, i.e. value added per worker corrected by the quantity of capital stock and land:

$$
g_{A, c}=\alpha_{k, c} g_{q, c}+g_{R e s, c} .
$$

When the model growth rate in output per worker exactly matches the observed growth rate of value added per worker, i.e. $g_{R e s, c}=0$, the model attributes the growth rate in product to capital quality. We compute the growth rate of the Solow residual as the growth rate of agricultural output per worker net of the growth rate of observed intermediate inputs multiplied by the corresponding factor shares.

Table 1 compares the growth rate of the Solow residual to the growth rate of quality of capital services multiplied by the capital share. Data on the growth rate of the Solow residual are from the FAO-based dataset published by the USDA-ERS. We focus on three 


\begin{tabular}{lrrrrrr}
\hline PERIODS: & \multicolumn{2}{c}{$1962-2012$} & \multicolumn{2}{c}{$1980-2012$} & \multicolumn{2}{c}{$1990-2012$} \\
& $(\mathrm{~A})$ & $(\mathrm{B})$ & $(\mathrm{A})$ & $(\mathrm{B})$ & $(\mathrm{A})$ & $(\mathrm{B})$ \\
\hline AUS & $1.48 \%$ & $0.17 \%$ & $1.39 \%$ & $0.13 \%$ & $1.61 \%$ & $0.12 \%$ \\
BGR & $1.33 \%$ & $0.16 \%$ & $1.28 \%$ & $0.18 \%$ & $1.38 \%$ & $0.20 \%$ \\
BRA & $2.56 \%$ & $0.13 \%$ & $3.47 \%$ & $0.16 \%$ & $3.22 \%$ & $0.19 \%$ \\
CAN & $1.77 \%$ & $0.76 \%$ & $2.41 \%$ & $0.72 \%$ & $2.10 \%$ & $0.58 \%$ \\
ESP & $3.39 \%$ & $0.28 \%$ & $3.20 \%$ & $0.33 \%$ & $3.32 \%$ & $0.35 \%$ \\
FRA & $2.28 \%$ & $0.83 \%$ & $3.05 \%$ & $0.98 \%$ & $3.43 \%$ & $1.05 \%$ \\
GBR & $1.40 \%$ & $1.07 \%$ & $1.14 \%$ & $1.09 \%$ & $1.16 \%$ & $1.07 \%$ \\
DEU & $2.59 \%$ & $0.47 \%$ & $3.16 \%$ & $0.56 \%$ & $3.27 \%$ & $0.60 \%$ \\
ITA & $3.13 \%$ & $0.24 \%$ & $3.34 \%$ & $0.28 \%$ & $3.61 \%$ & $0.30 \%$ \\
MEX & $2.20 \%$ & $-0.53 \%$ & $1.87 \%$ & $-0.69 \%$ & $2.27 \%$ & $-0.67 \%$ \\
NLD & $2.90 \%$ & $0.64 \%$ & $2.86 \%$ & $0.76 \%$ & $3.00 \%$ & $0.82 \%$ \\
SWE & $1.70 \%$ & $0.79 \%$ & $2.25 \%$ & $0.94 \%$ & $2.14 \%$ & $1.00 \%$ \\
USA & $1.72 \%$ & $0.65 \%$ & $1.77 \%$ & $0.68 \%$ & $1.99 \%$ & $0.63 \%$ \\
\hline
\end{tabular}

Table 1: Growth accounting exercise. Columns (A) report the growth rate of the Solow residual over the relevant period. Columns (в) report the growth rate of capital quality, as measured by our model, multiplied the capital share over the relevant period. Source: FAOStat and own computations based on quotes from tractorhouse.com.

sub-periods: 1962-2012, 1980-2012, and 1990-2012. Given the identity in equation 6, we can compute the fraction of the Solow residual explained by the growth in the quality of capital services:

$$
\frac{\alpha_{k, c} \mu_{q, c}}{g_{A, c}} .
$$

On average, capital quality explains $23 \%$ of the growth rate of the Solow residual. In the US, Canada and France capital quality explains about a third of the growth rate of the Solow residual. On the other hand, capital quality accounts for less than $10 \%$ of the growth rate of the Solow residual in Brazil, Spain and Italy.

Development accounting. We study the role of capital quality for income differences in agriculture value added across countries in year 2012 via standard development accounting exercises. We assume that cross-country disparities in the top quality of operated capital (and therefore average quality of operated capital) in 2012 are equal to those in 2014. 
First, we measure how successful is our model at explaining cross-country agricultural income differences. As in Caselli (2005), this amounts to ask the following question: suppose all countries had the same level of residual efficiency Res, how would the distribution of agricultural income per worker in our sample look like compared to the actual one? We measure observed agricultural value added per worker in 2012 by multiplying the value of gross agricultural production per worker by 1 minus the sum of intermediate inputs factor shares as published by the USDA-ERS. ${ }^{20}$ To compute agricultural value added in our model, we assume $\log$ utility and set $\beta$ to 0.95 to identify $R_{c}$ in balanced growth as: $R_{c}=\frac{\left(1+\alpha_{k, c} \mu_{c}\right)}{\beta}$. We compare the variation in agricultural value added per worker observed in the data, $\widetilde{y}^{d}$, to that predicted by our model, $\widetilde{y}$ :

$$
\frac{\operatorname{var}\left(\log \left(\widetilde{y}_{2012}\right)\right)}{\operatorname{var}\left(\log \left(\widetilde{y}_{2012}^{d}\right)\right)}=61.14 \%
$$

We find that the fraction of variance in agricultural value added per worker explained by our model is $61.14 \%$. If we were not to account for cross-country differences in capital quality that is, if we were to set $q_{\bar{j}, c} \widehat{q}_{\bar{j}, c}=1$ in each country, our model would explain only $40.70 \%$ of the cross-country variance in agricultural value added per worker in our sample. We conclude that capital quality accounts for $20.44 \%$ of cross-country variance in agricultural value added per worker in our sample, holding capital per worker fixed. Capital quality has an additional indirect effect not captured in our accounting exercise: capital stocks per worker endogenously increase in response to improvements in capital quality. Hence, we believe our result is a lower bound to the role of quality for disparities in agricultural labor productivity.

Second, using equation 5 , we decompose the difference in agricultural value added per worker in a given country with respect to the US in three main components: capital quality,

\footnotetext{
${ }^{20}$ Intermediate inputs include: crops materials (fertilizer, pesticide, seed), animal material (pharmaceuticals, feed) and livestock capital.
} 


\begin{tabular}{|c|c|c|c|c|c|c|}
\hline \multirow{2}{*}{\multicolumn{2}{|c|}{$\frac{\widetilde{y}_{U S, 2012}^{d}}{\widetilde{y}_{c, 2012}^{d}}$}} & \multicolumn{5}{|c|}{ PERCENTAGE OF $\log (\underbrace{d}_{\widetilde{y}_{c, 2012}^{d}})$ EXPLAINED BY: } \\
\hline & & $q_{\bar{j}}$ & $\widehat{q}_{\bar{j}}$ & $\widetilde{\vec{k}}$ & $\tilde{l}$ & Total \\
\hline BGR & 7.66 & $30.3 \%$ & $4.8 \%$ & $12.4 \%$ & $43.9 \%$ & $91.5 \%$ \\
\hline BRA & 2.58 & $39.4 \%$ & $-6.3 \%$ & $6.1 \%$ & $19.0 \%$ & $58.3 \%$ \\
\hline MEX & 5.37 & $26.1 \%$ & $-21.8 \%$ & $16.9 \%$ & $40.9 \%$ & $62.0 \%$ \\
\hline
\end{tabular}

Table 2: Development accounting: decomposition. The table reports the percentage contribution of each income component to a country's difference in agricultural value added per worker with respect to the US. Results are reported only for countries in the bottom quartile of the agricultural income distribution. Agricultural value added is measured in 2012 as gross agricultural production per worker multiplied by 1 minus the sum of intermediate inputs shares as from the USDA-ERS dataset. Factor shares and land endowments are inputed from the data as 2010-2012 averages. Source: FAOStat and own computations based on quotes from tractorhouse.com.

capital quantity, and land per worker, plus a residual term.

$$
\begin{aligned}
\log \left(\widetilde{y}_{U S, t}^{d}\right)-\log \left(\widetilde{y}_{c, t}^{d}\right)= & \underbrace{\alpha_{k, U S} \log \left(q_{\bar{j}_{t}, U S A}\right)-\alpha_{k, c} \log \left(q_{\bar{j}_{t}, c}\right)+\alpha_{k, U S A} \log \left(\widehat{q}_{\bar{j}, U S}-\alpha_{k, c} \log \left(\widehat{q}_{\bar{j}, c}\right)\right.}_{\text {capital quality }}+ \\
& \underbrace{\alpha_{k, U S} \log \left(\widetilde{k}_{U S A, t}\right)-\alpha_{k, c} \log \left(\widetilde{k}_{c, t}\right)}_{\text {capital quantity }}+\underbrace{\alpha_{l, U S} \log \left(\widetilde{l}_{U S A, t}\right)-\alpha_{l, c} \log \left(\widetilde{l}_{c, t}\right)}_{\text {land }}+ \\
& \log \left(\operatorname{Res}_{U S A}\right)-\log \left(\operatorname{Res}_{c}\right),
\end{aligned}
$$

The contribution of capital quality can be further divided into two components: differences in the top quality of capital operated in a country and differences in the average quality. Table 2 shows the result of this decomposition for countries in the bottom quartile of the agricultural income distribution in our sample. The two most important sources of differences in agricultural value added per worker are i) the top quality of operated equipment and ii) land endowments. The former accounts for between $30 \%$ and $40 \%$ of the percentage differences in agricultural value added per worker with the respect to the US in Bulgaria, Brazil and Mexico. The total contribution of capital quality on the income per worker differential with respect to the US is $36 \%$ for Bulgaria, $33 \%$ for Brazil and $4 \%$ for Mexico. This implies that the contribution of the range of operated qualities, $\widehat{q}_{\vec{j}}$, is negative for Brazil and Mexico and positive for Bulgaria. The higher arrival rate of the best available 


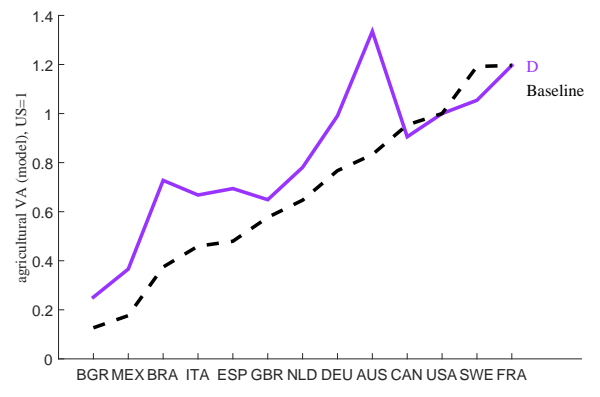

(a)

Figure 9: Development accounting: counterfactual. Model predicted agricultural value added per worker under the baseline (balck-striped line) and with US-valued quality of capital (violet-solid lines).

technology, $\mu$, results in a wider spread between the qualities of the best and worst operated technologies in the US compared to Brazil, Mexico and Bulgaria. At the same time, the higher capital intensity of agricultural production increases the role of capital quality for production in the US compared to the other three countries. The former effect prevails for the case of Brazil and Mexico while the opposite is true for the case of Bulgaria. We conclude that, on average, capital quality accounts for $24.33 \%$ of the difference in agricultural value added per worker between countries in the bottom quartile of the income distribution and the US, holding capital quantity per worker fixed.

Last, how would the cross-country distribution of agricultural value added per-worker look like if all countries were to have a quality of installed capital identical to that of the US? We use our model to compute the counterfactual output per worker in agriculture when all countries share the US-level of capital quality in 2012, i.e. $q_{\bar{j}_{2012}, c} \widehat{q}_{\bar{j}, c}=q_{\bar{j}_{2014}, U S A} \widehat{q}_{\bar{j}, U S}$. Figure 9 shows the counterfactual cross-country value added per worker distribution against the distribution that the model produces when all countries are attributed their own estimated quality of physical capital. The variance of the logarithm of agricultural output per worker decreases from 0.48 (baseline) to 0.21 (counterfactual). Moreover, the log differential in agricultural output per worker between the bottom quartile of the income distribution (i.e. Mexico, Brazil and Bulgaria) and the US decreases from to $90.5 \%$ to $45.7 \%$.

Overall, quality disparities in the stock of capital across countries are sizeable and 
contribute substantially to the disparate behavior of productivity in the agricultural sector.

\section{Discussion}

In this section, we would like to discuss incentives to quality adoption across countries. We discuss two mechanisms: a) barriers to adoption and b) production heterogeneity. The first one has a direct impact on adoption incentives and induced obsolescence, the second one is more subtle. Production heterogeneity may affect equilibrium pricing of used goods in the market. Hence, induced obsolescence and adoption may change in response to shifts in the scrap value of these goods.

First, we describe an economy in which the cost of adoption of different vintages of capital varies across countries. Unlike Parente and Prescott (1994), we do not need to restrict the growth rate of different countries to be the same. Indeed, we need these growth rates to differ across countries to be able to predict the differences in prices of old to new equipment observed in the data. The key insight that allows us to generate those patterns under the assumption of a common quality frontier, is that adoption costs depend on the speed of improvement of the frontier technology, but not necessarily on the level of quality. We are able to infer the cost of adoption across countries, and study their implications for the path of value added per worker via counterfactual exercises.

Second, we build a model of production heterogeneity in which dispersion in productivity across farms explains differences in the relative pricing of different quality of goods. However, conditional on the quality of a given stock, we show that the only determinant of obsolescence is the arrival of newer vintages (and higher qualities) to the economy. In other words, while differences in production heterogeneity (or farm level distortions) may explain why there are differences in the pricing of particular qualities relative to others, it cannot explain why once we control quality, obsolescence profiles differ across countries. If we were to introduce costly adoption of technologies as we do in the prior exercise, heterogeneity would not matter for adoption incentives. Heterogeneity is relevant in identifying differences in the average vintage composition of the stock of capital. We show that a stylized model 
with production heterogeneity generates the same pricing equation derived in the benchmark economy, and hence, the same implied path of best available qualities from the data, $\mu$.

\subsection{An economy with endogenous quality adoption}

We augment our baseline framework to allow for endogenous costly adoption of quality. The cost of adoption of improved quality is positively related to such quality, negatively related to the quality of the best adopted technology in the country, and decreases with the speed of innovation in quality around the world. In particular, the cost in terms of final goods of adopting technology, $q_{j+1}$ when the best available quality is $q_{\bar{j}}$ and the frontier quality improves at rate $\mu$, is:

$$
\begin{array}{rlc}
C\left(q_{j+1}, q_{\bar{j}}, \mu\right) & =\frac{q_{j+1}}{q_{\bar{j}}} \frac{1}{(1+\mu)} \tau & \text { if } q_{j+1}>q_{\bar{j}} \\
& =1 & o / w
\end{array}
$$

where $\tau$ is a country specific parameter that induces disparities in effective adoption costs.

The problem of technology adoption has been widely studied in the literature. The seminal work of Parente and Prescott (1994) analyzed this problem assuming that adoption costs depend on the level of the local technology relative to the world technology. Such assumption imposes tights conditions on the growth rate of technology improvement along the BGP. In particular, while levels of productivity are allowed to differ across countries, the rate of technological improvement is common across countries. The cost function that we assume in our paper allows us to construct economies where the rate of quality improvement differs across countries along the BGP. We show this next.

The problem of the representative household is:

$$
\max _{c_{t},\left\{x_{t}^{q_{j}}, q_{t+1}^{q_{j}}\right\}_{j \in A_{t+1}^{c}}} \sum_{t=0}^{\infty} \beta^{t} U\left(c_{t}\right),
$$


subject to:

$$
\begin{gathered}
c_{t}+\sum_{j \in A_{t+1}^{c}} C\left(q_{j+1}, q_{\bar{j}+1}, \mu\right) \pi_{t}^{q_{j}} x_{t}^{q_{j}} \leq \sum_{j \in A_{t}^{c}} r_{t}^{q_{j}} k_{t}^{q_{j}}+w_{t} n_{t}+r_{t}^{l} l_{t}, \\
\left(k_{t+1}^{q_{j}}-k_{t}^{q_{j}}(1-\delta) \chi\right)=x_{t}^{q_{j}} \quad \text { for all } j \in A_{t+1}^{c} .
\end{gathered}
$$

From the pricing condition, we obtain the standard euler equations,

$$
\begin{gathered}
\pi_{t}^{q_{j}} \geq \frac{\pi_{t+1}^{q_{j}}}{R_{t+1}}\left[\frac{r_{t+1}^{q_{j}}}{\pi_{t+1}^{q_{j}}}+(1-\delta)\right] \exp (-\lambda), \quad j \in A_{t}^{c} \\
C\left(q_{j+1}, q_{j+1}, \mu\right) \pi_{t}^{q_{j+1}} \geq \frac{\pi_{t+1}^{q_{j+1}}}{R_{t+1}}\left[\frac{r_{t+1}^{q_{j+1}}}{\pi_{t+1}^{q_{j}}}+(1-\delta)\right] \exp (-\lambda), \quad j>\bar{j}+1 .
\end{gathered}
$$

Because the return to any type of capital used in production is the same except through differences in quality (and those are fully accounted for in equilibrium prices) arbitrage implies:

$$
C\left(q_{j+1}, q_{\bar{j}+1}, \mu\right) \geq 1, \quad j>\bar{j}+1
$$

Hence, whenever the cost is relatively high, there is no adoption. The marginal quality adopted is such that the cost of adoption equals one.

$$
\frac{q_{j+1}}{q_{\bar{j}}} \frac{1}{(1+\mu)} \tau=1
$$

When there are no differences in adoption costs through distortions in the market, as summarized by $\tau=1$, the quality of the next available technology adopted is proportional to current technology by the rate of improvement in the frontier technology, $q_{j+1}=(1+\mu) q_{\bar{j}}$. Economies where the cost of adoption is relatively high, $\tau>1$, display a rate of adoption in quality that is lower than the improvement in frontier quality, $q_{j+1}=q_{j} \frac{(1+\mu)}{\tau}$.

If we go back to our pricing equation for used equipment, disparities in adoption costs can be identified using the estimated parameters of the regression,

$$
\ln \left(\widehat{p}_{t}^{k_{i}}(a)\right)=\ln \left(\frac{\lambda_{i t}(\tau)}{1-\psi \tau^{1-\alpha_{k}}}\right)+a \ln \left(\frac{(1-\delta) \tau}{(1+\mu)}\right)
$$


where $\lambda_{i t}=\frac{\alpha_{k} q_{\widetilde{j}_{t+1}}^{\alpha_{k}} \widetilde{l}^{\alpha_{l}}}{\left(\widehat{q_{\bar{j}}}(\tau) \widetilde{\delta} \tilde{k}(\tau)\right)^{1-\alpha_{k}}} \frac{(1-\lambda)}{R}$.

\subsubsection{Counterfactuals}

We run a policy experiment in which we increase the growth rate of capital quality in each country, $\mu$, by the average difference to France (1.49\%) and study the implications for agricultural output per worker. We choose France because it is the country with highest capital quality growth. The estimated growth of quality across countries is $1.49 \%$ lower than in France on average. If the common frontier grows at the rate in which quality grows in France, our policy is equivalent to lowering distortions $\tau$ by $1.49 \%$ on average.

For each country, we measure agricultural output per worker 10 years in the future, along the new balance growth path. Figure 10 plots the model predicted agricultural output in 2012 along with agricultural output in 2022 under the estimated path of quality and the counterfactual. Panels (b) and (c) of the same figure show the corresponding ten-year growth rates. While all countries improve value added relative to the US, gains differ across countries. The disparities are related to differences in the share of capital across countries. Countries that are relatively more intensive in capital benefit more from the fall in distortions and the gains in productivity are larger.

\subsection{Equilibrium capital prices and production heterogeneity ${ }^{21}$}

In this section we augment our benchmark model to allow for production heterogeneity. We assume there is a continuum of farms differentiated by their productivity $z, \Omega \equiv[\underline{z}, \bar{z}]$. Assume that capital goods of different quality are perfect substitutes in production and that there are decreasing returns to capital ${ }^{22}$. Everything else equal, each production unit will

\footnotetext{
${ }^{21}$ The full description of the economy can be found in the appendix, here we describe the key predictions of the model.

${ }^{22}$ In this section I abstract away from labor and land. Both can be introduced into the analysis as long as we maintain the assumption of overall decreasing returns to scale (so that the distribution of production over farm productivity is not degenerate).
} 


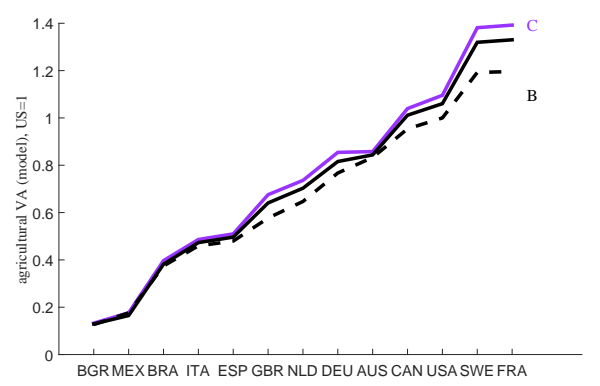

(a)

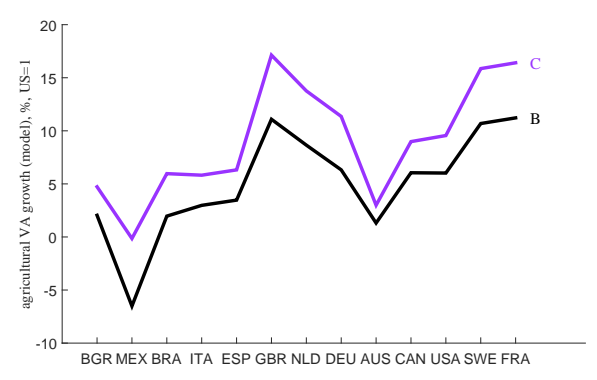

(b)

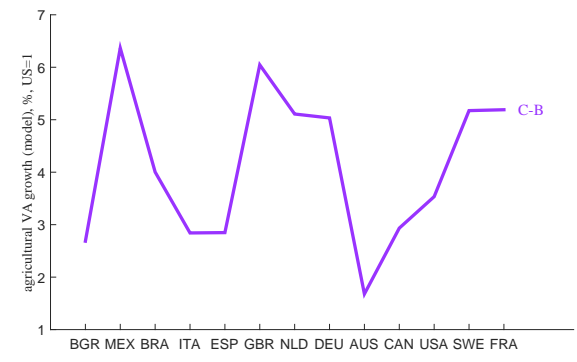

(c)

Figure 10: Counterfactual exercise. Model predicted agricultural output per worker under the baseline path of capital quality in 2012 (black-striped line, "B") and in 2022 (black-solid lines) vs. Model predicted agricultural output per worker under the counterfactual path of quality in 2022 (violet-solid lines , "C").

fully specialize in a particular vintage of capital. The problem of each production unit is:

$$
\max _{k_{i}} z_{j}\left(q_{i} k_{i}\right)^{\alpha}-r_{i} k_{i}
$$

Farms endogenously sort across different capital qualities. Let $\Omega_{i}$ be the set of farm types (productivities) that use quality $q_{i}$. In equilibrium, the sorting of farms is such that the relative supply (in efficiency units) of alternative capital qualities equalizes the relative productivity of farms using them,

$$
\frac{\int_{\Omega_{i^{\prime}}} z_{s}^{\frac{1}{1-\alpha}} d s}{\int_{\Omega_{i}} z_{s}^{\frac{1}{1-\alpha}} d s}=\frac{q_{i^{\prime}} K^{i^{\prime}}}{q_{i} K^{i}} .
$$

where $K^{i}$ is the total supply of capital of vintage i. This condition implies that independently 
of the distribution of productivities across farms, the equilibrium allocation across vintages adjusts as a function of the relative supply of each vintage. It is therefore critical to study the pricing of durables in an environment in which the sorting of farms across equipment quality is endogenous.

The price of new equipment is then,

$$
p_{t}^{k^{q^{\bar{j}}}}=\alpha\left(\frac{\int_{\Omega_{t+1}^{\bar{j}}} z_{i}^{\frac{1}{1-\alpha}} d i}{\delta K}\right)^{1-\alpha}\left(q_{t+1}^{\bar{j}}\right)^{\alpha} \frac{(1-\lambda)}{R} \frac{1}{1-\frac{(1-\delta)(1-\lambda)}{R(1+\mu)^{1-\alpha}}}
$$

The price increases in the quality of the vintage, but also in the productivity of the firms that operate it.

The price of an $a$-years old piece of equipment at time $t$ reads:

$$
\widehat{p}_{t}^{q_{j}}(a)=(1-\delta)^{a} p_{t}^{k^{q_{1}}}=\left(\frac{\int_{\Omega_{t}^{\bar{j}}} z_{i}^{\frac{1}{1-\alpha}} d i}{\delta K}\right)^{1-\alpha}\left(q_{t}^{\bar{j}}\right)^{\alpha}\left(\frac{(1-\delta)}{(1+\mu)^{1-\alpha}}\right)^{a} \frac{\frac{(1-\lambda)}{R}}{1-\frac{(1-\delta)(1-\lambda)}{R(1+\mu)^{1-\alpha}}}
$$

If we compute the logarithm of the price of an $a$ years old piece of equipment, we obtain

$$
\ln \left(\widehat{p}_{t}^{q_{j}}(a)\right)=\ln \psi\left(q_{t}^{\bar{j}}\right)+a \ln \left(\frac{(1-\delta)}{(1+\mu)^{(1-\alpha)}}\right)
$$

where $\psi\left(q_{t}^{\bar{j}}\right)$ is a constant. The elasticity of the price to changes in age is analogous to the one described in the accounting exercise under the benchmark model. The only difference is that, due to the decreasing returns assumption, induced obsolescence depends on the span of control $\alpha$.

Note that changes in the distribution of productivities that different farms use for production affects the price of a particular quality relative to another. Consider two countries where the best available technologies are $q_{t}^{\bar{j}}$ and $q_{t}^{\bar{i}}$. The ratio of the constants in equation 
5.2 depends on the average productivity using each of these qualities in each country,

$$
\frac{\psi\left(q_{t}^{\bar{j}}\right)}{\psi\left(q_{t}^{\bar{i}}\right)}=\frac{\int_{\Omega_{t}^{\bar{j}}} z_{i}^{\frac{1}{1-\alpha}} d i}{\int_{\Omega_{t}^{\bar{i}}} z_{i}^{\frac{1}{1-\alpha}} d i}\left(\frac{K_{t}^{\bar{i}}}{K^{\bar{j}}}\right)^{\alpha}
$$

However, once we control for quality disparities, the obsolescence of a particular good is unaffected by the productivity of the farms using it. The arrival of new technologies, the physical depreciation rate and the intensity of capital in production are the only determinants of the price decay with age.

\section{Conclusions}

In this paper, we explore the implications of disparate patterns of capital embodied technology adoption for agricultural productivity differences across countries. To do so, we construct a novel dataset of prices of second-hand equipment (tractors) that allows us to control for capital quality differences. Using our model, we infer the path of quality of installed capital in a given economy from the age-price profile of tractors of a given vintage. //On average, richer countries have both higher growth rates and levels of capital quality. Our inferred growth rate of capital quality has a correlation of 0.57 with agricultural value added per worker in 2012, while our inferred top capital quality has a correlation of 0.36 .

We study the role of capital embodied technology for labor productivity in the agricultural sector via standard growth and income accounting exercises. We conclude that $24 \%$ of cross-country differences in agricultural value added growth between 1980 and 2012 that are unaccounted for by observable factors can be attributed to capital quality disparities. When each country is given a quality of installed capital stock identical to that of the US, the variance of the logarithm of output per worker decreases from 0.48 to 0.21 and the log differential in output per worker between the bottom quartile of the income distribution (i.e. Mexico, Brazil and Bulgaria) and the US decreases from to $90.5 \%$ to $45.7 \%$.

Understanding adoption patterns and their relationship to the market structure of used 
durable goods and pricing patterns is a promising avenue for future research. 


\section{References}

Adamopoulos, T., and D. Restuccia (2014): "The Size Distribution of Farms and International Productivity Differences," American Economic Review, 104(6), 1667-97.

Akerlof, G. A. (1970): "The Market for "Lemons": Quality Uncertainty and the Market Mechanism," The Quarterly Journal of Economics, 84(3), 488-500.

Benhabib, J., And A. Rustichini (1991): "Vintage capital, investment, and growth," Journal of Economic Theory, 55(2), 323-339.

Caselli, F. (2005): "Accounting for Cross-Country Income Differences," in Handbook of Economic Growth, ed. by P. Aghion, and S. Durlauf, vol. 1 of Handbook of Economic Growth, chap. 9, pp. 679-741. Elsevier.

Chari, V. V., and H. Hopenhayn (1991): "Vintage Human Capital, Growth, and the Diffusion of New Technology," Journal of Political Economy, 99(6), 1142-65.

Donovan, K. (2014): "Agricultural Risk, Intermediate Inputs, and Cross-Country Productivity Differences," Manuscript.

Fuglie, K. (2015): “Accounting for Growth in Global Agriculture," Bio-based and Applied Economics, (4).

Gavazza, A., A. Lizzeri, And N. Roketskiy (2014): "A Quantitative Analysis of the Used-Car Market," American Economic Review, 104(11), 3668-3700.

Gollin, D., D. Lagakos, And M. E. Waugh (2014): "The Agricultural Productivity Gap," The Quarterly Journal of Economics, 129(2), 939-993.

GriLiches, Z. (1961): "Hedonic Price Indexes for Automobiles: An Econometric of Quality Change," in The Price Statistics of the Federal Goverment, NBER Chapters, pp. 173-196. National Bureau of Economic Research, Inc.

Hoff, K., A. Braverman, And J. Stiglitz (eds.) (1993): The economics of rural organization : theory, practice, and policy. Oxford University Press.

Hulten, C., J. Robertson, and F. Wycoff (1989): "Energy Obsolescence and the Productivity Slowdown," in D. Jorgenson and R. Landau, eds "Technology and Capital Formation". 
Jorgenson, D. W., And Z. Griliches (1967): "The Explanation of Productivity Change," The Review of Economic Studies, 34(3), 249-283.

Jovanovic, B., And Y. Yatsenko (2012): "Investment in vintage capital," Journal of Economic Theory, 147(2), 551 - 569, Issue in honor of David Cass.

Manuelli, R., And A. Seshadri (2014): "Frictionless Technology Diffusion: The Case of Tractors," American Economic Review, 104(4), 1368-91.

MCGuiRK, A., AND Y. MundlaK (1991): "Incentives and constraints in the transformation of Punjab agriculture:," Discussion paper.

Parente, S. L., And E. C. Prescott (1994): "Barriers to Technology Adoption and Development," Journal of Political Economy, 102(2), 298-321.

Ramankutty, N., A. Evan, C. Monfreda, and J. Foley (2008): "Farming the planet: 1. Geographic distribution of global agricultural lands in the year 2000," Global Biochemical Cycles, 22.

Restuccia, D., D. T. YAng, and X. Zhu (2008): "Agriculture and aggregate productivity: A quantitative cross-country analysis," Journal of Monetary Economics, 55(2), $234-250$.

Sims, B., And J. Kienzle (2009): "Farm equipment supply chains," Discussion paper.

Solow, R. (1957): "Technical Change and the Aggregate Production Function," Review of Economics and Statistics, 39, 312-320.

Stolyarov, D. (2002): "Turnover of Used Durables in a Stationary Equilibrium: Are Older Goods Traded More?," Journal of Political Economy, 110(6), 1390-1413.

Sunding, D., And D. Zilberman (2001): "The agricultural innovation process: Research and technology adoption in a changing agricultural sector," in Handbook of Agricultural Economics, ed. by B. L. Gardner, and G. C. Rausser, vol. 1, chap. 4, pp. 207-261. Elsevier. 


\section{A Proofs}

\section{Proof. Proposition 1}

In an interior solution, the relative cost of different vintages should equalize their relative quality,

$$
\frac{q_{2}}{q_{1}}=\frac{r_{t}^{q_{2}}}{r_{t}^{q_{1}}}
$$

If for example, $\frac{q_{2}}{q_{1}}>(<) \frac{r_{t}^{q_{2}}}{r_{t}^{q_{1}}}$, there is no demand for $k_{t}^{q_{1}}\left(k_{t}^{q_{2}}\right)$. Such condition is monotone in the quality differential, which proves our result.

\section{Proof. Proposition 2}

Guess: The quality of the bounds for the best and worst vintages used in production, $\underline{j}_{t}$ and $\bar{j}_{t}$ respectively, grow proportional to the growth rate of the best available quality in the market, $g_{q_{\bar{j}_{t}}}=\mu$. Capital per worker is constant, $\widetilde{k}_{t}$ as well as investment in the top technology, $\widetilde{x}_{t}^{q_{\bar{j}}}=\widetilde{x}_{t}$. The growth rate of output per capita is proportional to the growth rate of the quality of the best available vintage, i.e. $g_{\widetilde{y}}=\alpha_{k} \mu$.

Under our guess, we can de-trend output by $q_{\bar{j}_{t}}^{\alpha_{k}}$ to obtain

$$
\frac{\widetilde{y}_{t}}{q_{\underline{j}_{t}}^{\alpha_{k}}}=\left(\sum_{j \in A_{t}} \frac{q_{j}}{q_{\bar{j}_{t}}} \frac{\widetilde{k}_{t}^{q_{j}}}{\widetilde{k}_{t}}\right)^{\alpha_{k}} \widetilde{k}_{t}^{\alpha_{k}} \widetilde{l}^{\alpha_{l}}
$$

which is a constant if $\sum_{j \in A_{t}} \frac{q_{j}}{q_{\bar{j}_{t}}} \frac{\widetilde{k}_{t}^{q_{j}}}{\widetilde{k}_{t}}$ is a constant. We have guessed that the bounds of $A_{s}$ grow at rate $\mu^{23}$. Hence $\sum_{j \in A_{t}} \frac{q_{j}}{q_{\bar{j}_{t}}} \frac{\widetilde{k}_{t}^{q_{j}}}{\widetilde{k}_{t}}$ is a constant if the distribution of capital per worker across vintages used in production is constant in time. That is, the share of total capital accounted for by a vintage that is $n$ lags away from the top available in a given period is constant. To show this, we describe the law of motion for capital,

$$
\begin{gathered}
\widetilde{k}_{t}^{q_{\overline{j_{t}}}}=\widetilde{x}_{t} \\
\widetilde{k}_{t}^{q_{\bar{j}_{t-1}}}=(1-\lambda)(1-\delta) \widetilde{k}_{t-1}^{q_{\bar{j}_{t-1}}}=(1-\lambda)(1-\delta) \widetilde{x}_{t}
\end{gathered}
$$

Hence, the total amount of capital in any period is described as

$$
\sum_{\underline{j}_{t}}^{\bar{j}_{t}-1}((1-\lambda)(1-\delta))^{\bar{j}_{t}-1-j} \widetilde{x}=\widetilde{k}
$$

For investment to be constant if capital is constant we need that the distance between the best and worst vintages in production is a constant, i.e. $\underline{j}_{t}=\bar{j}_{t}-\theta$ for some $\theta>0$. This is

\footnotetext{
${ }^{23}$ Alternatively, one could have assumed away the random retirement of capital (at rate $\lambda$ ). In this case, there are infinitely many vintages operated at each point in time. Given the optimal investment strategy for capital, the BGP is preserved since $\sum_{j=-\infty}^{\bar{j}_{t}} \frac{q_{j}}{q_{\bar{j}_{t}}} \delta(1-\delta)^{\bar{j}_{t}-j}$ is a geometric series with infinitely many terms.
} 
true because the expected time of a vintage of capital in the market is $T(j)=\frac{1}{\lambda}$, so $\theta=T(j)$ satisfies our restriction. This also implies that the quality of the best and worst technology operated are proportional to each other, with $q^{\underline{\underline{j}}} t=\frac{q^{\bar{j}} t}{(1+\mu)^{\frac{1}{\lambda}}}$.

Solving for the optimal investment level, we obtain

$$
\widetilde{x}=\widetilde{k} \frac{(1-(1-\lambda)(1-\delta))}{\left(1-((1-\lambda)(1-\delta))^{T(j)}\right)}
$$

which is a constant. To build intuition, note that if $\lambda$ equals 1 , so that the full stock of capital is retired every period, investment equals the total stock of capital. When $\lambda \rightarrow 0$ and the expected time to retirement goes to infinity, investment corresponds to the depreciated part of the aggregate stock each period, $\widetilde{x}=\delta \widetilde{k}$. From now on, let $\widehat{\delta}=\frac{(1-(1-\lambda)(1-\delta))}{\left(1-((1-\lambda)(1-\delta))^{T(j)}\right)}$, so along the BGP investment per worker is $\widetilde{x}=\widehat{\delta} \widetilde{k}$. If investment is accounted in efficiency units, $\pi^{q_{\bar{j}}} \widetilde{x}$ it grows proportionally to the growth rate of the best available quality, $\alpha_{k} \mu$. The price of quality which equals the present discounted value of the stream of dividends is

$$
\pi^{q_{\bar{j}}}=\frac{\alpha_{k} q_{\bar{j}}^{\alpha_{k}} \widetilde{l}^{\alpha_{l}}}{\left(\widehat{q_{\bar{j}}} \widehat{\delta} \tilde{k}\right)^{1-\alpha_{k}}} \frac{(1-\lambda) \beta}{1-(1-\lambda)(1-\delta) \beta}
$$

with dividends given by $\frac{\alpha_{k} q_{\bar{j}}^{\alpha_{k}} \tilde{l}^{\alpha_{l}}}{\left(\widehat{q_{\bar{j}}} \widehat{\bar{\delta}}\right)^{1-\alpha_{k}}}=r^{q_{\bar{\jmath}}}$ where the vintage composition of the stock of capital can be summarized by $\widehat{q_{\bar{j}}}=\left(\sum_{j \in A_{t}} \frac{q_{j}}{q_{\bar{j}}}(1-\delta)^{\bar{j}-j}\right)$.

To pin down the level of capital in steady state, we need to return to the euler equation of the households,

$$
1 \geq \beta(1-\lambda)\left[\frac{r^{q_{\bar{j}}}}{\pi^{q_{\bar{j}}}}+(1-\delta)\right]
$$

Given that in an economy without trend, the production technology for output and capital is the same (it is a one sector economy), the relative price of capital to consumption should equal 1 ,

$$
1=\frac{\pi^{q_{\bar{j}}}}{q_{\bar{j}}^{\alpha_{k}}} \equiv \frac{\alpha_{k} \widetilde{l}^{\alpha_{l}}}{\left(\widehat{q_{\bar{j}}} \widetilde{\delta} \widetilde{k}\right)^{1-\alpha_{k}}} \frac{(1-\lambda) \beta}{1-(1-\lambda)(1-\delta) \beta}
$$

which pins down the stock of capital per worker, $\widetilde{k}^{*}$, as a function of land per worker, the quality of stocks in operation and parameters. The price of the best available technology raises at rate $g_{\pi^{q_{\bar{j}}}}=\alpha_{k} g_{Q}$

Finally, the feasibility constraint of the economy dictates

$$
\widetilde{c}_{t}=\widetilde{y}_{t}-\pi_{t}^{q_{\bar{j}}} \widehat{\delta} \widetilde{k}^{*}
$$

Hence, consumption, output and investment per worker grow at the same rate $\alpha_{k} \mu$ and we can verify our initial guess. 


\section{A.1 Description of equilibrium, heterogeneity in production}

The optimality conditions imply that if the aggregate supply of capital of any quality $i$ is $K^{i}$, equilibrium returns can be characterized as

$$
r^{i}=\alpha \frac{\left(q_{i}\right)^{\alpha}}{\left(K^{i}\right)^{1-\alpha}}\left(\int_{\Omega_{i}} z_{s}^{\frac{1}{1-\alpha}} d s\right)^{1-\alpha}
$$

where $\Omega_{i}$ is the set of productivity levels of production units that use quality $i^{24}$ Let $\pi\left(z_{j}, i\right)$ denote equilibrium profits for a firm with productivity $z_{j}$ using vintage $i$. To be able to determine $\Omega_{i}$ for each possible type of quality available, we need to use an indifference condition. Suppose that there is a countable set of qualities (as it is the case when qualities arrive every period at rate $\mu$ ). Firms will only switch qualities whenever the profits obtained by using such quality are higher than using a slightly worse quality. For the firm that is indifferent across two vintages $i$ or $\widehat{i}$ with $i<\widehat{i}$, the following condition holds

$$
\pi\left(z^{*}, i\right)=\pi\left(z^{*}, \widehat{i}\right)
$$

Hence, firms with productivity above $z^{*}$ choose the better quality $\widehat{i}$, and those below $z^{*}$ choose the worst quality. In determining the marginal firm in the market, both the quality differential, as well as the relative supply of each capital type are important. The relative supply of older vintages of capital is always lower than that of newer equipment (because households only invest in the top available technology and capital depreciates). This indifference condition provides a key relationship to predicting obsolescence profiles and the equilibrium price of equipment,

For each of these goods, there will be an equilibrium price that clears the market, so the vintage would be in the market until retired. The equilibrium price is

$$
p_{t}^{k^{q_{j}}}=\sum_{s=t+1}^{\infty} \frac{(1-\delta)^{s-(t+1)}(1-\lambda)^{s-t}}{\prod_{h=0}^{s-t+1} R_{t+1+h}} \alpha \frac{\left(q_{j}\right)^{\alpha}}{\left(K_{s}^{j}\right)^{1-\alpha}}\left(\int_{\Omega_{s}^{j}} z_{i}^{\frac{1}{1-\alpha}} d i\right)^{1-\alpha}
$$

where $\Omega_{s}^{j}$ corresponds to the set of firms that purchase vintage $j$ at time $s$.

${ }^{24}$ With these prices, we can compute optimal capital demand and equilibrium profits

$$
\begin{gathered}
k_{i, j}=K^{i} \frac{\left(z_{j}\right)^{\frac{1}{1-\alpha}}}{\int_{\Omega_{i}} z^{\frac{1}{1-\alpha}} d s} \\
\pi\left(z_{j}, i\right)=(1-\alpha) z_{j}\left(q_{i} K^{i}\right)^{\alpha} \frac{\left(z_{j}\right)^{\frac{\alpha}{1-\alpha}}}{\left(\int_{\Omega_{i}} z_{s}^{\frac{1}{1-\alpha}} d s\right)^{\alpha}}
\end{gathered}
$$

Hence, both are proportional to the productivity of the farm relative to the average productivity of all the firms using that particular vintage of equipment. 
The price of a new machine corresponds to

$$
\widehat{p}_{t}^{k_{\bar{j}}}=p_{t}^{k_{\bar{j}}^{q_{\bar{j}}}}
$$

whereas the price of an $a$ years old machine corresponds to

$$
\widehat{p}_{t}^{q_{j}}(a)=(1-\delta)^{a} p_{t}^{k^{q_{1}}}
$$

Define $w_{s}^{j}(t)$ as the ratio between the average productivity of firms using technology $j$ at time $s$, and the average productivity of firms using the best available technology at time $t$, i.e. $w_{s}^{j}(t)=\frac{\left(\int_{\Omega_{s}^{j}} z_{i}^{\frac{1}{1-\alpha}} d j\right)^{1-\alpha}}{\left(\int_{\Omega_{t}^{j}} z_{i}^{1-\alpha} d i\right)^{1-\alpha}}$. If along the BGP the vintage composition of the stock of capital is constant, we can infer that

$$
w_{s}^{j}(t)=\left(\frac{(1-\delta)}{(1+\mu)}\right)^{(1-\alpha)(s-t)}
$$

Hence, the relative average productivity of firms using alternative vintages of capital is fully determined by the depreciation rate and the arrival of new quality.

\section{B Details on the quantitative analysis}

\section{B.1 Factor shares}

Factor shares are computed from the shares published by the USDA-ERS by assuming constant returns to scale in labor, land, and capital. Table 3 shows factor shares for the countries in our sample, as averages for the period 1980-2012

\section{B.2 Physical depreciation}

We identify the depreciation rate of physical capital in each country from the slope of the hour-price profile of the average-quality tractor in each country. To outline our identification strategy, consider two tractors of identical quality but different hours of usage. Tractors A and $\mathrm{B}$ are both $a$-yearS old but, differently from tractor A, tractor B was used in production and has positive hours of usage. The price difference between the two tractors reflects physical depreciation:

$$
p_{B}=p_{A} \Theta\left(u_{B}\right),
$$

where $u_{B}$ is the amount of hours tractor B was operated and $\Theta\left(u_{B}\right)$ is the opportunity costs of these hours. Assume that $\Theta(u)=(1-\delta)^{u / \operatorname{avg}(u)}$, where $\operatorname{avg}(u)$ is the "usual" amount of hours a tractor is operated in a given period of time, i.e. a year for a yearly depreciation 


\begin{tabular}{lrrr}
\hline & $\alpha_{n}$ & $\alpha_{l}$ & $\alpha_{k}$ \\
\hline AUS & $18 \%$ & $68 \%$ & $14 \%$ \\
BGR & $31 \%$ & $56 \%$ & $14 \%$ \\
BRA & $57 \%$ & $26 \%$ & $17 \%$ \\
CAN & $72 \%$ & $4 \%$ & $24 \%$ \\
ESP & $70 \%$ & $15 \%$ & $15 \%$ \\
FRA & $61 \%$ & $15 \%$ & $24 \%$ \\
GBR & $32 \%$ & $31 \%$ & $37 \%$ \\
DEU & $61 \%$ & $15 \%$ & $24 \%$ \\
ITA & $70 \%$ & $15 \%$ & $15 \%$ \\
MEX & $24 \%$ & $42 \%$ & $34 \%$ \\
NLD & $61 \%$ & $15 \%$ & $24 \%$ \\
SWE & $61 \%$ & $15 \%$ & $24 \%$ \\
USA & $38 \%$ & $37 \%$ & $25 \%$ \\
\hline
\end{tabular}

Table 3: Factor sharesL 1980-2012 average. Source: USDA-ERS.

rate. Then, $\delta$ is the implied rate of physical depreciation of tractor B:

$$
\delta=1-\left(\frac{p_{B}}{p_{A}}\right)^{\frac{1}{u_{B} / a v g(u)}} .
$$

This argument generalizes to tractors with different hours of usage for a given age, $a$. In each country, we use our dataset on retail prices to evaluate equation 9 for synthetic tractors with average characteristics at different hours of usage. We set $\operatorname{avg}(u)$ to the average yearly hours of usage in our US sample, 302 hours, and define the set of hours at which we evaluate equation 9 to include $12 \operatorname{avg}(u)$-size increments from zero, $U=\{302,604, \ldots, 3624\}$. The rate of depreciation in country $c$ is the average depreciation rate resulting from evaluating equation 9 at each $u \in U$ :

$$
\delta_{c}=\frac{1}{11} \sum_{u \in U}\left(1-\frac{\hat{p}_{c}(u+1)}{\hat{p}_{c}(u)}\right),
$$

where $\hat{p}_{c}(u)$ is the predicted price for country $c$ of the tractor with average characteristics, average age and $u$ hours of usage, as predicted by our estimation in Table 5 , column (1). ${ }^{25}$ The final estimates are shown in Table 4.

\footnotetext{
${ }^{25}$ Given the results of the baseline estimation in Section 2, for each country $c$ we predict:
}

$$
\hat{p}_{c}(u)=\left(\hat{\theta_{1}} \hat{\gamma}_{c}+\hat{\theta_{1}} \hat{\beta}_{a, c} \bar{a}+\hat{\theta_{1}} \hat{\beta}_{\text {hours }} \frac{u \hat{\theta_{2}}-1}{\hat{\theta_{2}}}+\hat{\theta_{1}} \hat{\beta} \frac{\bar{X}_{c,-a,- \text { hours }}-1}{\hat{\theta_{2}}}+1\right)^{\frac{1}{\theta_{1}}},
$$




\begin{tabular}{lr}
\hline & Physical depreciation: $\delta$ \\
\hline AUS & $2.35 \%$ \\
BGR & $2.62 \%$ \\
BRA & $2.59 \%$ \\
CAN & $2.20 \%$ \\
ESP & $2.40 \%$ \\
FRA & $2.31 \%$ \\
GBR & $2.40 \%$ \\
DEU & $2.40 \%$ \\
ITA & $2.28 \%$ \\
MEX & $2.48 \%$ \\
NLD & $2.32 \%$ \\
SWE & $2.26 \%$ \\
USA & $2.18 \%$ \\
\hline
\end{tabular}

Table 4: Inferred physical depreciation. Source: own computations based on quotes from tractorhouse.com.

\section{B.3 Top technology}

We identify the top technology operated in each country from the country-specific dummy as predicted by our model in equation 4 . These dummies depend on the top technology operated in country $c$ in a given year, $q_{\bar{j}_{t+1, c}}$, as follows:

$$
e^{\gamma_{1, c}}=\frac{\alpha_{k, c} q_{\bar{j}_{t+1}, c^{\alpha_{k}}}^{\alpha_{k, c} \widetilde{l}_{c}^{\alpha_{l, c}}}}{\left(\widehat{q}_{\bar{j}, c} \widehat{\delta}_{c}{\widetilde{k_{c}}}^{1-\alpha_{k, c}}\right.} \frac{(1-\lambda)}{R_{c}}\left(\frac{1}{1-\frac{(1-\lambda)\left(1-\delta_{c}\right)}{\left(1+\mu_{c}\right)^{1-\alpha_{k, c} R_{c}}}}\right) .
$$

Note that under balanced growth, the vintage composition of the stock of capital can be computed as a function of the top technology only, and steady state investment in physical capital. The top quality operated in country $c$ in a given year relative to that of the US is:

$$
\frac{q_{\bar{j}_{t+1}, c}}{q_{\bar{j}_{t+1}, U S}}=\left(\frac{D_{c}}{D_{U S}}\left(\widetilde{k}_{U S A} q_{\bar{j}_{t+1}, U S}\right)^{\alpha_{k, U S}-\alpha_{k, c}}\left(\frac{\widetilde{k}_{c}}{\widetilde{k}_{U S A}}\right)^{1-\alpha_{k, c}}\right)^{\frac{1}{\alpha_{k, c}}}
$$

where the bar operator indicates averages, the hat operator indicates estimates and $\beta$ is a vector of coefficients on tractor characteristics other than age and hours, $X_{-a,- \text { hours }}$. 
for $D_{c}=e^{\gamma_{1, c}}\left(1-\frac{(1-\lambda)\left(1-\delta_{c}\right)}{R_{c}\left(1+\mu_{c}\right)^{1-\alpha_{k, c}}}\left(\frac{R_{c}}{1-\lambda} \frac{\left(\widehat{(}_{c} \widehat{q}_{\bar{j}}, c\right)^{1-\alpha_{k, c}}}{\widetilde{l}_{c}^{\alpha_{l, c}}}\right)\right)$. We normalize the top-quality and output per worker in agriculture to equal one in the US in $2014, q_{\bar{j}_{2014}, U S}=1$ and $\widehat{y}_{U S, 2014}=1$. These normalizations combined with the previous normalization on land per worker imply a value for the steady state capital per worker in the US is:

$$
\widetilde{k}_{U S A}=\frac{1}{\widehat{q}_{\bar{j}}, U S \widehat{\delta}_{U S}} .
$$

For a given value of a tractor's expected lifetime $T=\frac{1}{\lambda}$, which we set to 15 years, we can identify cross-country differences in the top quality operated in 2014 from equation 10. 
B.4 Estimation results 
Table 5: Estimation results for Retail

\begin{tabular}{|c|c|c|c|c|c|}
\hline & Retail & & Matc & 1 data & \\
\hline & (1) & (2) & (3) & $(4)$ & $(5)$ \\
\hline Country Dummy *age & & & & & \\
\hline Australia & -0.142 & -0.259 & -0.271 & -0.269 & -0.256 \\
\hline & $(0.035)$ & $(0.052)$ & $(0.055)$ & $(0.049)$ & $(0.055)$ \\
\hline Bulgaria & -0.135 & & & & \\
\hline & $(0.037)$ & & & & \\
\hline Brazil & -0.125 & -0.0964 & -0.0983 & -0.103 & -0.00902 \\
\hline & $(0.017)$ & $(0.058)$ & $(0.060)$ & $(0.056)$ & $(0.082)$ \\
\hline Canada & -0.226 & -0.335 & -0.336 & -0.318 & -0.282 \\
\hline & $(0.005)$ & $(0.016)$ & $(0.016)$ & $(0.015)$ & $(0.016)$ \\
\hline France & -0.221 & -0.319 & & -0.304 & \\
\hline & $(0.018)$ & $(0.029)$ & & $(0.027)$ & \\
\hline Germany & -0.165 & -0.298 & -0.298 & -0.275 & -0.224 \\
\hline & $(0.007)$ & $(0.010)$ & $(0.011)$ & $(0.009)$ & $(0.012)$ \\
\hline Italy & -0.149 & -0.331 & -0.334 & -0.314 & -0.279 \\
\hline & $(0.028)$ & $(0.064)$ & $(0.064)$ & $(0.061)$ & $(0.059)$ \\
\hline Mexico & -0.0174 & & & & \\
\hline & $(0.051)$ & & & & \\
\hline Netherlands & -0.17 & -0.211 & -0.224 & -0.203 & -0.199 \\
\hline & $(0.018)$ & $(0.029)$ & $(0.032)$ & $(0.028)$ & $(0.043)$ \\
\hline Spain & -0.159 & -0.144 & & -0.133 & \\
\hline & $(0.042)$ & $(0.086)$ & & $(0.081)$ & \\
\hline Sweden & -0.223 & & & & \\
\hline & $(0.035)$ & & & & \\
\hline United Kingdom & -0.21 & -0.423 & -0.421 & -0.412 & -0.306 \\
\hline & $(0.018)$ & $(0.022)$ & $(0.022)$ & $(0.021)$ & $(0.027)$ \\
\hline United States & -0.202 & -0.308 & -0.308 & -0.294 & -0.261 \\
\hline & $(0.002)$ & $(0.007)$ & $(0.007)$ & $(0.007)$ & $(0.008)$ \\
\hline Controls & & & & & \\
\hline Horsepower & 4.823 & 7.314 & 7.333 & 6.931 & 8.507 \\
\hline & $(0.016)$ & $(0.037)$ & (0.038) & $(0.036)$ & $(0.084)$ \\
\hline Hours & -0.461 & -1.108 & 0.491 & -1.012 & 3.26 \\
\hline & $(0.016)$ & $(0.043)$ & $(1.156)$ & $(0.040)$ & $(3.960)$ \\
\hline Wage*hours & & & -1.06 & & -2.388 \\
\hline & & & $(0.767)$ & & $(2.697)$ \\
\hline$\theta_{1}$ & 0.148 & 0.19 & 0.19 & 0.185 & 0.185 \\
\hline & $(0.004)$ & $(0.005)$ & $(0.006)$ & $(0.006)$ & $(0.006)$ \\
\hline$\theta_{2}$ & 0.105 & 0.148 & 0.146 & 0.14 & 0.139 \\
\hline & $(0.005)$ & $(0.007)$ & $(0.007)$ & $(0.007)$ & $(0.007)$ \\
\hline Observations & 28,305 & 20,932 & 20,702 & 20,702 & 20,702 \\
\hline $\mathrm{R} 2$ & 0.924 & 0.922 & 0.922 & 0.923 & 0.931 \\
\hline Likelihood & -321442 & -238763 & -236258 & -238662 & -236159 \\
\hline Other Controls & & & & & \\
\hline Dummy by crop & $\mathrm{N}$ & $\mathrm{N}$ & $\mathrm{N}$ & $\mathrm{Y}$ & $\mathrm{Y}$ \\
\hline
\end{tabular}

Notes: All regressions include dummies by country and manufacture. Horsepower is measured in hundreds units of horse power, and hours in ten thousands of hours of usage. All regressions allows for right hand side (hours, horsepower and age) transformation with coefficient $\theta_{2}$ and left hand side transformation with coefficient $\theta_{1}$. Columns (1) Uses data on retail. Column (2)-(5) use matched data for wich we use the information of the type of crop as control in some specifications. Standard errors in parenthesis. 
Table 6: Model-based estimation results for Retail

\begin{tabular}{|c|c|}
\hline & log price \\
\hline \multirow{2}{*}{$\begin{array}{r}\text { Country Dummy } * \\
\text { Australia }\end{array}$} & \\
\hline & $\begin{array}{c}0.245 \\
(0.122)\end{array}$ \\
\hline Brazil & $\begin{array}{r}-0.0736 \\
(0.108)\end{array}$ \\
\hline Canada & $\begin{array}{c}0.629 \\
(0.095)\end{array}$ \\
\hline France & $\begin{array}{l}(0.095) \\
0.28 \\
(0.126)\end{array}$ \\
\hline Germany & $\begin{array}{c}0.475 \\
(0.103)\end{array}$ \\
\hline Italy & $\begin{array}{c}0.369 \\
(0.099)\end{array}$ \\
\hline Mexico & $\begin{array}{c}0.304 \\
(0.096)\end{array}$ \\
\hline Netherlands & $\begin{array}{c}0.284 \\
(0.118)\end{array}$ \\
\hline Spain & $\begin{array}{l}-0.122 \\
(0.131)\end{array}$ \\
\hline Sweden & $\begin{array}{c}0.339 \\
(0.117)\end{array}$ \\
\hline United Kingdom & $\begin{array}{c}0.597 \\
(0.137)\end{array}$ \\
\hline United States & $\begin{array}{l}0.589 \\
(0.095)\end{array}$ \\
\hline \multirow{2}{*}{$\begin{array}{r}\text { Country Dummy *age } \\
\text { Australia }\end{array}$} & \\
\hline & $\begin{array}{l}-0.0355 \\
(0.007)\end{array}$ \\
\hline Bulgaria & $\begin{array}{l}-0.038 \\
(0.008)\end{array}$ \\
\hline Brazil & $\begin{array}{r}-0.0337 \\
(0.004)\end{array}$ \\
\hline Canada & $\begin{array}{r}-0.0533 \\
(0.001)\end{array}$ \\
\hline France & $\begin{array}{l}-0.0427 \\
(0.008)\end{array}$ \\
\hline Germany & $\begin{array}{r}-0.0569 \\
(0.004)\end{array}$ \\
\hline Italy & $\begin{array}{l}-0.053 \\
(0.004)\end{array}$ \\
\hline Мexico & $\begin{array}{c}-0.0436 \\
(0.001)\end{array}$ \\
\hline Netherlands & $\begin{array}{c}-0.0389 \\
(0.006)\end{array}$ \\
\hline Spain & $\begin{array}{c}-0.00962 \\
(0.012)\end{array}$ \\
\hline Sweden & $\begin{array}{l}-0.0497 \\
(0.005)\end{array}$ \\
\hline United Kingdom & $\begin{array}{l}-0.0549 \\
(0.007)\end{array}$ \\
\hline United States & $\begin{array}{l}-0.0479 \\
(0.000)\end{array}$ \\
\hline $\begin{array}{l}\text { Controls } \\
\text { Horsepower }\end{array}$ & $\begin{array}{l}-0.0391 \\
(0.004)\end{array}$ \\
\hline Hours & $\begin{array}{l}1.162 \\
(0.005)\end{array}$ \\
\hline$\theta_{2}$ & $\begin{array}{l}-0.041 \\
(0.004)\end{array}$ \\
\hline Constant & $\begin{array}{r}5.065 \\
-0.181\end{array}$ \\
\hline Observations & 28,305 \\
\hline R-squared & 0.924 \\
\hline 11 & -5303 \\
\hline
\end{tabular}

Notes: The regressions include dummies by manufacture. The logarithm of the price is the dependent variable. The regression allows for a Box-Cox transformation on the right hand side (hours, horsepower and age) with coefficient $\theta_{2}$. Standard errors in parenthesis. 